\title{
Study of the pathology and the underlying molecular mechanism of tissue injury around hematoma following intracerebral hemorrhage
}

\author{
JINGLEI WANG $^{1,2}$, YING CHEN ${ }^{1}$, JINGJING LIANG ${ }^{1}$, MAOSHENG CAO $^{1}$, JIABING SHEN ${ }^{1}$ and KAIFU KE ${ }^{1}$ \\ ${ }^{1}$ Department of Neurology, Affiliated Hospital of Nantong University; \\ ${ }^{2}$ Medical College, Nantong University, Nantong, Jiangsu 226001, P.R. China
}

Received September 21, 2020; Accepted May 19, 2021

DOI: $10.3892 / \mathrm{mmr} .2021 .12341$

\begin{abstract}
Intracerebral hemorrhage (ICH) refers to hemorrhage caused by spontaneous rupture of blood vessels in the brain. Brain injury due to ICH leads to catastrophic effects resulting from the formation of hematoma and oxidative stress caused by components of lysed erythrocytes. However, not all neurons in the area surrounding the hematoma die immediately: A number of neurons remain in a critical, but reversible, state; however, the genes involved in this critical state remain poorly understood. Gene chip technology was used identify changes in the area surrounding the hematoma associated with the upregulation of 210 and downregulation of 173 genes. Gene Ontology functional annotation revealed changes in the gene expression profile in the peripheral region of hematoma following $\mathrm{ICH}$, which were primarily associated with the external stimulation received by the organism, the transmission of harmful information to the cell through the transport of cell membrane proteins, and the regulation of a series of biological processes. Protein interaction network analysis revealed that 11 up-[secreted phosphoprotein 1, dual specificity phosphatase 9, catechol-O-methyltransferase, BAR/IMD domain-containing adaptor protein 2-like 1, plakophilin 2, homer scaffold protein 3, ret proto-oncogene (RET), KIT proto-oncogene, receptor tyrosine kinase, hepsin, connector enhancer of kinase suppressor of Ras 2 and kalirin RhoGEF kinase] and four downregulated genes (transcription factor AP-2 $\beta$, peptidylprolyl isomerase A, SHOC2 leucine rich repeat scaffold protein and synuclein $\alpha$ ) may serve a significant role in the area around hematoma following ICH. Reverse transcription-quantitative PCR was used to verify that these
\end{abstract}

Correspondence to: Dr Jiabing Shen or Professor Kaifu Ke, Department of Neurology, Affiliated Hospital of Nantong University, 20 Xisi Road, Chongchuan, Nantong, Jiangsu 226001, P.R. China

E-mail: shenjb0818@ntu.edu.cn

E-mail: kekaifu_nt@126.com

Key words: intracerebral hemorrhage, nervous repair, bioinformatics, rat, ret proto-oncogene genes were differentially expressed in the ICH compared with the control group. Causal network analysis suggested that the Achaete-scute homolog 1-RET signaling axis served a key role in the repair of nerve injury in the peripheral region of hematoma following $\mathrm{ICH}$. Additionally, in vivo experiments revealed that RET expression was upregulated and co-localized with neurons. Taken together, these results suggested that the changes in the gene expression profile in the area around hematoma following ICH were primarily associated with the repair of damage caused to the nervous system.

\section{Introduction}

Intracerebral hemorrhage (ICH) refers to cerebral parenchymal hemorrhage caused by spontaneous rupture of cerebral blood vessels. It is one of the subtypes of cerebral apoplexy, accounting for $20-30 \%$ of all cerebral apoplexy in China $(1,2)$. $\mathrm{ICH}$ is a common disorder in the field of neurology. The treatment methods available for $\mathrm{ICH}$, such as intravenous mannitol, remain limited, and the mortality rate of the acute stage is $30-40 \%$. The majority of survivors exhibit sequelae, such as dyspraxia, cognitive impairment and speech and deglutition disorder $(2,3)$. The high mortality and disability rates $(\sim 40 \%$ and $90 \%$ ) associated with this disease are costly in terms of the pain and burden caused to both families and society $(3,4)$. As the population ages worldwide, the harm caused by $\mathrm{ICH}$ becomes increasingly acute $(4,5)$.

Current research suggests that ICH not only comprises primary lesions caused by hematoma (for example, hematoma formation and the placeholder effect of expansion, which cause direct damage to tissue around the hematoma), but also includes toxic substances triggered by the burst of erythrocytes, high metabolic state, spreading depression, oxidative stress, toxic effects of excitatory amino acids and inflammation of the tissue surrounding the hematoma, which causes secondary damage (6-8). The secondary neuronal damage caused by ICH contributes towards neurological impairment, which manifests as neuronal apoptosis and glial activation and proliferation $(9,10)$. Similarly to 'ischemic penumbra' in cerebral infarction, the tissue around the hematoma is provisionally termed a perihematoma 'microenvironment', due to the lack of a definite definition. With ongoing pathological 
damage, these cells gradually die or undergo proliferation and activation, thereby aggravating neurological function defects and resulting in death of the tissue $(11,12)$.

With the completion of the Human Genome Project, the number of known gene sequences has been growing at an unprecedented rate. Traditional experimental methods, such as de novo protein sequencing, have been unable to systematically interpret the increasing amount of gene sequence information (13). Gene chip technology, also known as DNA chip or microarray, which was developed in the late 1980s, aims to study polymorphism and expression changes of numerous genes in a variety of physiological and pathological contexts for high-throughput analysis to assess their function, interaction and regulatory association (14-16). Investigation of both the molecular mechanisms underpinning changes in the perihematoma microenvironment following $\mathrm{ICH}$ and the regulatory associations of the molecular protein network will provide better understanding of the pathological mechanisms underlying $\mathrm{ICH}$, thereby assisting in the development of drugs for use in the clinic and therapeutic intervention strategies.

\section{Materials and methods}

Animals and reagents. A total of 80 male specific-pathogen-free Sprague-Dawley rats (age, 8-9 weeks; weight, 220-260 g; mean weight, $240 \mathrm{~g}$ ) were obtained from the Department of Animal Center, Medical College of Nantong University. All animals were raised in a temperature- and humidity-controlled room $\left(22 \pm 1^{\circ} \mathrm{C}\right.$; 55-65\%) with a 12-h light/dark cycle and food and water were available ad libitum. Primary antibodies against pro caspase-3 (cat. no. ab32499), cleaved caspase-3 (cat. no. ab32042), NeuN (cat. no. ab279290), ret proto-oncogene (RET; cat. no. ab134100) and $\beta$-tubulin (cat. no. ab18207), secondary goat anti-rabbit IgG H\&L (cat.no. ab6721) and rabbit anti-mouse IgG (cat.no. ab6728) and Hoechst 33342 Staining Dye Solution (cat. no. ab228551) were purchased from Abcam. The ECL Western Blot Substrate (cat. no. ab65623) were purchased from Abcam. The secondary Alexa Fluor ${ }^{\circledR}-488$ (anti-mouse; cat. no. A-11029) and Alexa Fluor $^{\circledR}$-568 (anti-rabbit; cat. no. A-11036) antibodies were purchased from Thermo Fisher Scientific, Inc. The BCA protein quantitation kit, tissue total protein lysis buffer, PMSF and fluorescent sealing solution were from Beyotime Institute of Biotechnology; PVDF membrane and protease inhibitor were from Roche Diagnostics. Blotting paper was purchased from Bio-Rad Laboratories, Inc.

Construction of the ICH model and animal grouping. ICH model rats were anesthetized intraperitoneally with sodium pentobarbital $(30 \mathrm{mg} / \mathrm{kg})$. The body position of the rats was straightened, and the head was fixed. The top of the head was locally prepared and routinely disinfected (17). A central sagittal incision of $\sim 1.5 \mathrm{~cm}$ was made on the top of the head to expose the skull. The caudate nucleus was located on one side of the brain by stereotactic localization (the fontanelle was used as the reference median point; forward, 0.2; lateral, 3.5 ; depth, $5.5 \mathrm{~mm}$ ) and the return needle was $0.5 \mathrm{~mm}$. For the operation group, $50 \mu \mathrm{l}$ autogenous blood was injected at a rate of $10 \mu \mathrm{l} / \mathrm{min}$; for the sham operation group, the same method was used to insert the needle but without injection. The needle was retained for $10 \mathrm{~min}$ and sutured.
Rats were randomly divided into normal (control), sham and post-ICH groups (6 and $12 \mathrm{~h}$, and 1, 2, 3, 5, 7 and 9 days; these times refer to the time points after the intracerebral hemorrhage and at these time points the behavioral experiments and tissue extraction were performed; $n=6$ rats/group). At the end of the study, rats were anesthetized by intraperitoneal injection of sodium pentobarbital $(30 \mathrm{mg} / \mathrm{kg})$ until they lost consciousness. All animals were sacrificed following anesthesia by exsanguination.

Forelimb placing test. The trunk of the rat was suspended, and the forelimbs were allowed to move freely. The whiskers on one side of the rat were quickly brushed. When the forelimb of the same side reflexively extended to the corner of the table, one point was recorded. The two forelimbs of each rat were tested 10 times each. The lower the score, the more severe was the impairment of nerve function, as shown by the difficulty of forelimb placement on the opposite side of the injury following ICH (18).

Corner turn test. Two pieces of wood were fixed to form an included angle of $30^{\circ}$. After entering the included angle, rats were able to exit by turning left or right, and the data were recorded. The experiment was repeated 10-15 times for each rat, with a time interval of $\geq 30 \mathrm{sec}$ between repeats, and the number of left or right turns was calculated. Under normal circumstances, rats are equally likely to turn left or right; however, rats are more inclined to turn to the injured side than to the opposite side following ICH (19).

Western blot analysis. Brain tissue was collected from the perihematoma region (distance, $\leq 3 \mathrm{~mm}$ ), and protein lysate ( $1 \mathrm{ml} / 100 \mathrm{mg}$ ) was added. The compound was homogenized at $4^{\circ} \mathrm{C}$ and centrifuged $(12,000 \mathrm{x}$ for $10 \mathrm{~min})$ following $30 \mathrm{~min}$ incubation on ice. Subsequently, the supernatant was removed, and the protein concentration was determined via the BCA method. A small amount of supernatant $(\sim 50 \mu \mathrm{l})$ was divided into EP tubes and stored at $-80^{\circ} \mathrm{C}$. For western blotting analysis, $10 \mu \mathrm{g}$ total protein was resolved by SDS-PAGE on $10 \%$ gels and then transferred onto PVDF membranes. Skimmed milk powder blocking solution (5\%) was then added to the prepared films, and the membranes were shaken at room temperature for $2 \mathrm{~h}$ (or overnight at $4^{\circ} \mathrm{C}$ ). After sealing the membrane, the corresponding primary antibody was incubated at $4^{\circ} \mathrm{C}$ with the membrane, which was allowed to rest at room temperature for $8-10 \mathrm{~h}$, or at $4^{\circ} \mathrm{C}$ overnight. The dilution factor of cleaved-caspase 3 was 1:500; RET and GAPDH were both $1: 1,000$. The membrane was subsequently incubated with the secondary antibody $(1: 10,000)$, the plate was flipped at room temperature for $1 \mathrm{~h}$ and the films were developed using ECL. GAPDH was used as the loading control. ImageJ v1.8.0.112 (National Institutes of Health) was used for densitometry.

Immunohistochemistry. At the aforementioned time points following the construction of the ICH model, tissue was fixed in $4 \%$ paraformaldehyde at $4^{\circ} \mathrm{C}$ for $12 \mathrm{~h}$. Subsequently, the fixed tissue was dehydrated with $20-30 \%$ sucrose solution sequentially ( $20 \%$ for 1 day, then $30 \%$ for 1 day). When the tissue had sunk to the bottom of the bottle, the tissue was removed and placed on a frozen slicer with $5 \%$ sucrose solution or OCT as 
Table I. Primer sequences.

\begin{tabular}{|c|c|}
\hline Primer & Sequence, 5'-3' \\
\hline \multirow[t]{2}{*}{ COMT } & F: AGAATGCAAAGCCTGGAGAC \\
\hline & R: GCTGTACTCCCGAATCACTG \\
\hline \multirow[t]{2}{*}{ KIT } & F: CCATCAAAGCTATCCCAGTGG \\
\hline & R: ACCGTAAATGTGTCCCCTTC \\
\hline \multirow[t]{2}{*}{ SPP1 } & F: GGTTTGCTTTTGCCTGTTCG \\
\hline & R: CTGAGTGTTTGCTGTAATGCG \\
\hline \multirow[t]{2}{*}{$\mathrm{HPN}$} & F: GGGTTCAGGCTGTGATCTATC \\
\hline & R: CGGCTGGATGTATTCTGTGAG \\
\hline \multirow[t]{2}{*}{ RET } & F: CCTTCTACCAGTTCCGCATG \\
\hline & R: CCGTCCCCTTCTAAGAGTTTG \\
\hline \multirow[t]{2}{*}{ DUSP9 } & F: CССТААССТТССТААССТСТТТG \\
\hline & R: AGATTCTGGCTCCAATGATCAG \\
\hline \multirow[t]{2}{*}{ PKP2 } & F: GCAGACTTAGAGATGACCTTGG \\
\hline & R: ACCCTTTTCCGTGCTTCAG \\
\hline \multirow[t]{2}{*}{ HOMER3 } & F: GCTACGAAGAGGAACTGGATTC \\
\hline & R: TGAAGGTCATGTTGGGAGTG \\
\hline \multirow[t]{2}{*}{ KALRN } & F: CCCAAAACACCAGCCAAAC \\
\hline & R: GTCACTCTCCACTGTGTTCTG \\
\hline \multirow[t]{2}{*}{ CNKSR2 } & F: CAACACCAAAACAAGACAGCC \\
\hline & R: GGACTGGCACAACTCATAGAG \\
\hline \multirow[t]{2}{*}{ BAIAP2L1 } & F: CTACТTCTAССТTCAАAGCССC \\
\hline & R: ATCGGTCATTGGTCACTGTC \\
\hline \multirow[t]{2}{*}{ TFAP2B } & F: CTGGGCTCTGTGTCTCAAG \\
\hline & R: GAGTACGGGTCTTGACTTTGG \\
\hline \multirow[t]{2}{*}{ SNCA } & F: CTGCCACTGGTTTTGTCAAG \\
\hline & R: CTTCCAGGATTCCCTCTTGTG \\
\hline \multirow[t]{2}{*}{ PPIA } & F: CAAGACTGAGTGGCTGGATG \\
\hline & R: GGCTTCCACAATGCTCATG \\
\hline \multirow[t]{2}{*}{ SHOC2 } & F: CCTTTGGATTTTGGAACTTGGAC \\
\hline & R: AGAGAAACAAGACCAGACACG \\
\hline \multirow[t]{2}{*}{$\beta$-actin } & F: CAACTGGGACGATATGGAGAAG \\
\hline & R: TCTGGGTCATCTTTTCACGG \\
\hline
\end{tabular}

COMT, catechol-o-methyltransferase; KIT, kit proto-oncogene; SPP1, secreted phosphoprotein 1; HPN, hepsin; RET, ret protooncogene; DUSP9, dual specificity phosphatase 9; PKP2, plakophilin 2; HOMER3, homer scaffold protein 3; KALRN, kalirin rhoGEF kinase; CNKSR2, connector enhancer of kinase suppressor of ras 2; BAIAP2L1, BAR/IMD domain containing adaptor protein 2 like 1 ; TFAP2B, transcription factor AP-2 $\beta$; SNCA, synuclein $\alpha$; PPIA, peptidylprolyl isomerase A; SHOC2, SHOC2 leucine rich repeat scaffold protein; $\mathrm{F}$, forward; $\mathrm{R}$, reverse.

an embedding agent at $-20^{\circ} \mathrm{C}$. Coronal section of the brain was performed, and the thickness of the slices was $5 \mu \mathrm{m}$. The frozen sections were attached to adhesive slides, marked and stored at $4^{\circ} \mathrm{C}$ for later use. The tissue sections were washed 3 times with PBS (10 min each). The sealing solution (5\% BSA) was added and placed in a wet box for incubation at $37^{\circ} \mathrm{C}$ for $30 \mathrm{~min}$. The solution was discarded, and primary cleaved caspase-3 (1:100; cat. no. ab32042), NeuN (1:1,000; cat. no. ab279290) and RET (1:100; cat. no. ab134100; all Abcam) antibodies were added and incubated overnight at $4^{\circ} \mathrm{C}$. The sections were
Table II. Thermocycling conditions used for PCR.

\begin{tabular}{lccc}
\hline Stage & Cycles & Temperature, ${ }^{\circ} \mathrm{C}$ & Duration \\
\hline Initial denaturation & 1 & 95 & $5 \mathrm{~min}$ \\
Thermocycling & 40 & 95 & $10 \mathrm{sec}$ \\
& & 60 & $30 \mathrm{sec}$ \\
Solubility curve & 1 & 95 & $15 \mathrm{sec}$ \\
& & 60 & $60 \mathrm{sec}$ \\
& & 95 & $15 \mathrm{sec}$ \\
\hline
\end{tabular}

again washed 3 times with PBS (10 min each). The secondary antibody was subsequently added and incubated either at room temperature for $2 \mathrm{~h}$ or at $4^{\circ} \mathrm{C}$ overnight (both of these methods can be used to incubate the secondary antibodies, and the appropriate method can be chosen according to the arrangement of experiment time). The sections were washed 3 times with PBS (10 min each). Nuclear dye (1:1,000; Hoechst 33342) was added, and the tissue sections were incubated at room temperature for $10 \mathrm{~min}$. The sections were washed again three times with PBS (10 min each). Water droplets were absorbed from the surface, and the fluorescent sealing solution was added carefully to ensure that there were no bubbles. After standing at room temperature for $2 \mathrm{~h}$ in the dark, each section was observed and recorded under a laser confocal microscope (magnification, x4, x10, x20, x40 and x100). ImageJ v1.8.0.112 (National Institutes of Health) was used for analysis.

RNA extraction and microarray hybridization in rat brain tissue. Gene-chip hybridization and data-reading experiments were performed by CapitalBio Technology. The RNA purity (measured as the absorbance ratio A260/A280) was $\geq 1.80$; total RNA was $\geq 1 \mu \mathrm{g}$; RNA integrity was detected by formaldehyde denaturing gel electrophoresis, and the electrophoretic band of the RNA sample was found to be clear; $28 \mathrm{~S}$ : $18 \mathrm{~S}$ ribosomal RNA band brightness ratio was $\geq 1: 1$ and the quality of the RNA met the requirements of the expression profile chip. In accordance with the manufacturer's instructions, the hybridization was performed in an Agilent Hybridization Oven overnight at a rotation speed of $20 \mathrm{rpm}$ at $42^{\circ} \mathrm{C}$. An Agilent Microarray Scanner was used to scan the chip images, which were subsequently analyzed using Agilent image analysis software (GeneSpring software v12; Agilent Technologies, Inc.).

Bioinformatics analysis. After it had been confirmed that the quality of RNA resulting from each chip experiment was consistent, the RNA with significant differences in expression $(\log 2 \geq 1$ or $\leq-1$ and $\mathrm{P}<0.05)$ was screened using the calibration F test. Principal component analysis (PCA) of differentially expressed genes was then performed (http://bonsai.hgc. $\mathrm{jp} / \sim$ mdehoon/software/cluster/software.htm). Hierarchical clustering was used to compare genes with the control group to identify approximate relational classification (different pathways in which different genes are expressed) of up- and downregulated genes [Cluster 3.0 (https://cluster2.software. informer.com/3.0/) and Java Treeview (http://jtreeview. sourceforge.net/)] (20). Gene set enrichment analysis (GSEA) was performed by applying GSEA v2.2.3 to the Entrez Gene 
A

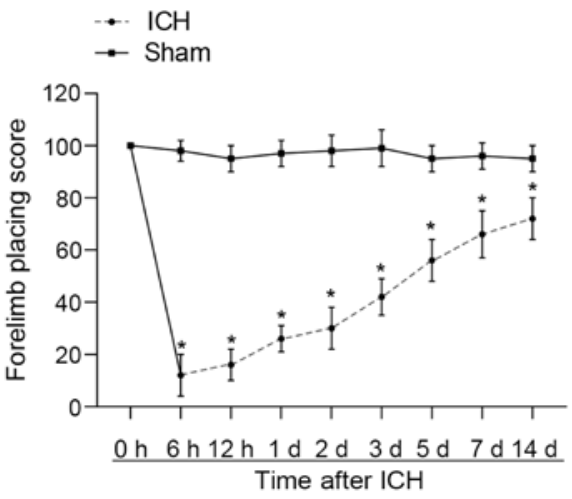

B

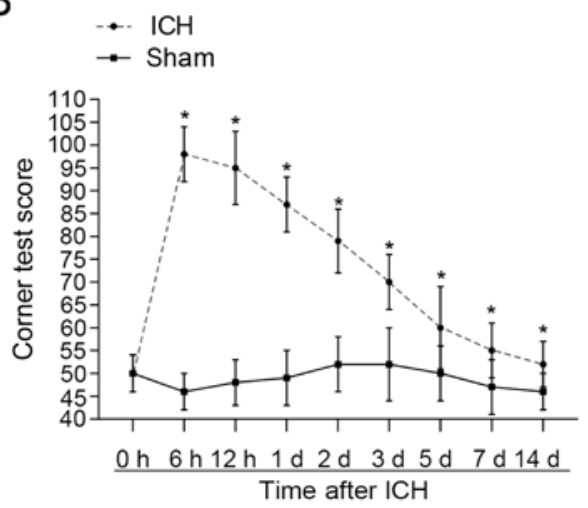

Figure 1. Neurological deficits score. (A) Limb placement and (B) corner turn test were used to detect limb functional defects following ICH in rats (n $\leq 12$ ). ${ }^{*} \mathrm{P}<0.05$ vs. sham. ICH, intracerebral hemorrhage; d, day.

A

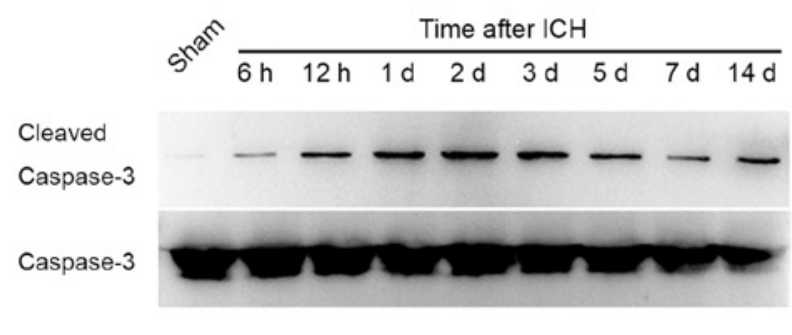

C
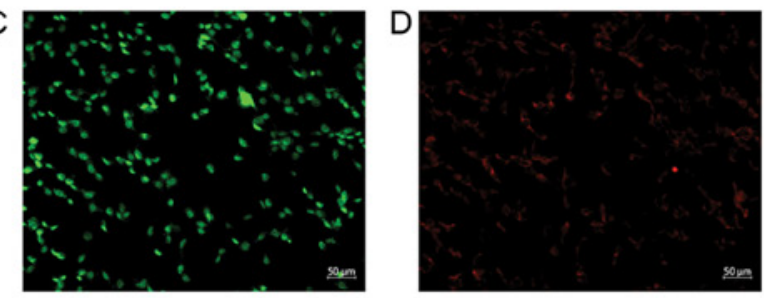

G
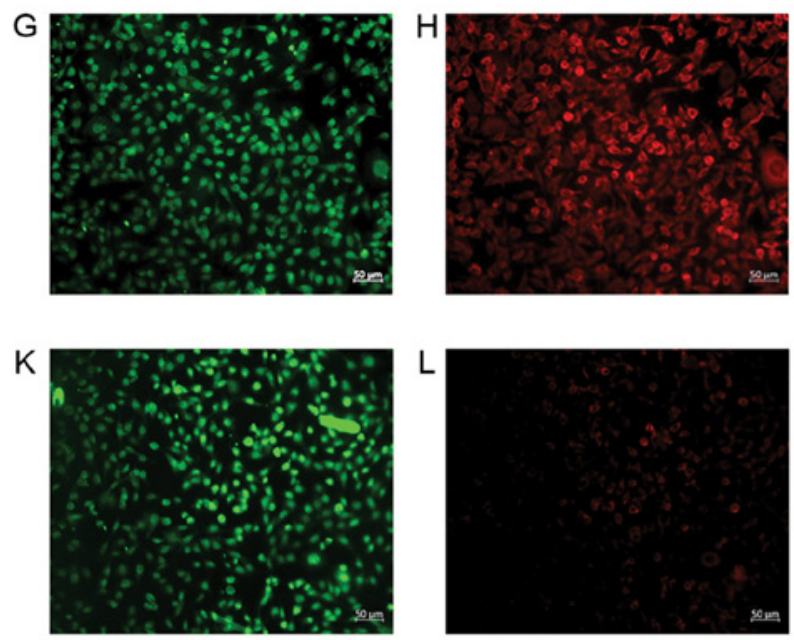

B
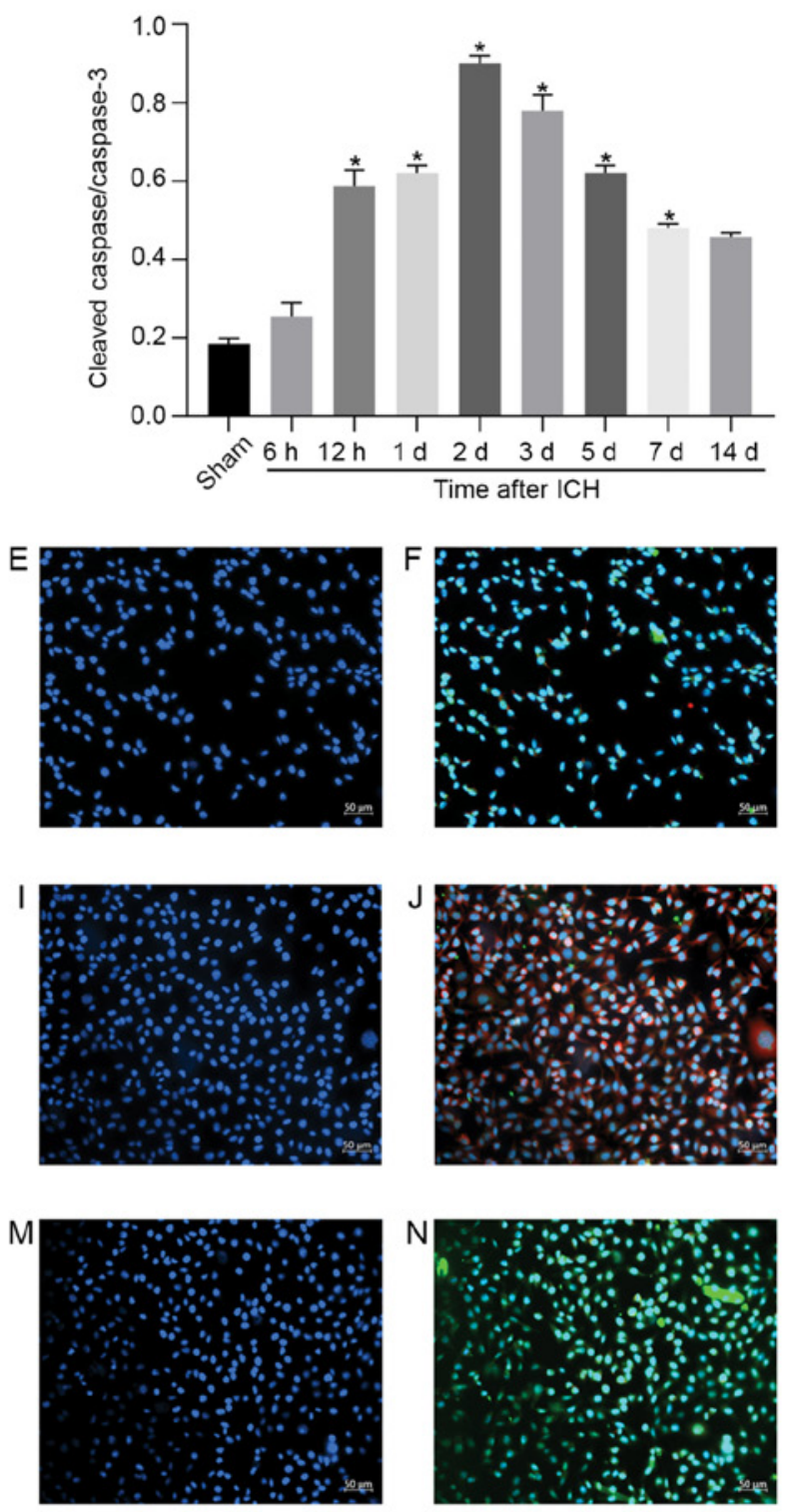

Figure 2. Apoptosis of neurons in the perihematoma following ICH. (A) Protein expression levels and (B) semi-quantification of caspase-3 and cleaved caspase-3. Immunofluorescence of (C) NeuN, (D) cleaved caspase-3 and (E) Hoechst staining in the perihematoma region of the sham group. (F) Merged staining of the sham group $(n=6)$. Immunofluorescence of $(\mathrm{G}) \mathrm{NeuN},(\mathrm{H})$ cleaved caspase-3 and (I) Hoechst staining in the perihematoma region at $2 \mathrm{~d}$ after ICH. (J) Merged staining at $2 \mathrm{~d}$ post-ICH. Immunofluorescence of (K) NeuN, (L) cleaved caspase-3 and (M) Hoechst staining in the perihematoma region at $7 \mathrm{~d}$ post-ICH. (N) Merged staining at $7 \mathrm{~d}$ post-ICH. "P<0.05 vs. sham. ICH, intracerebral hemorrhage; d, day. 
A

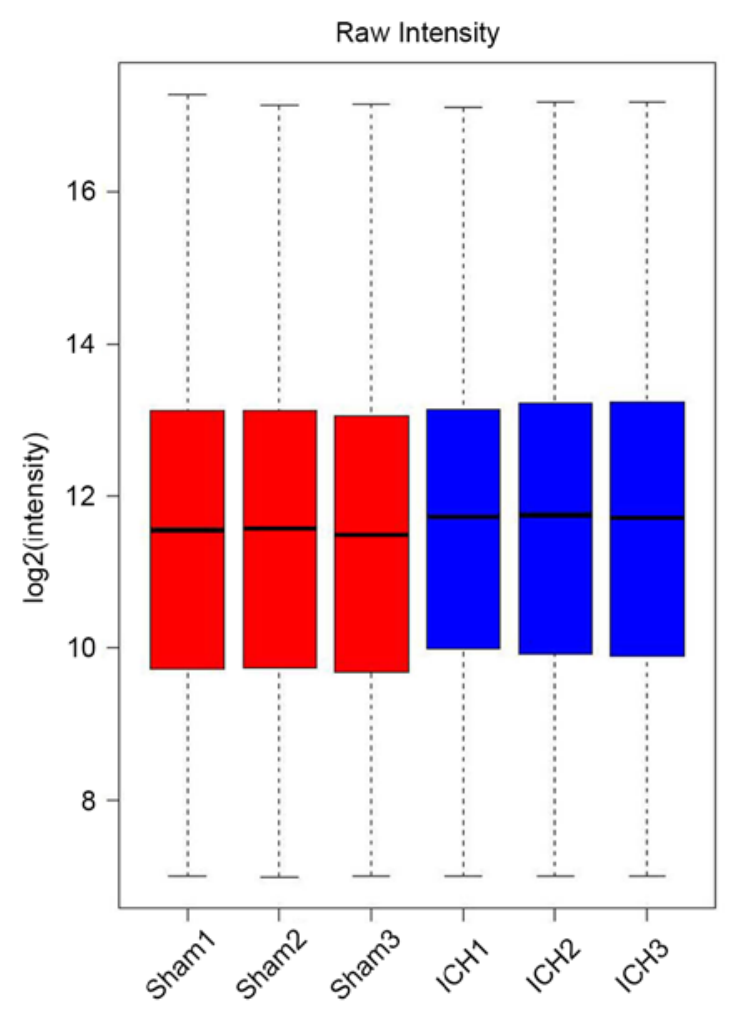

B

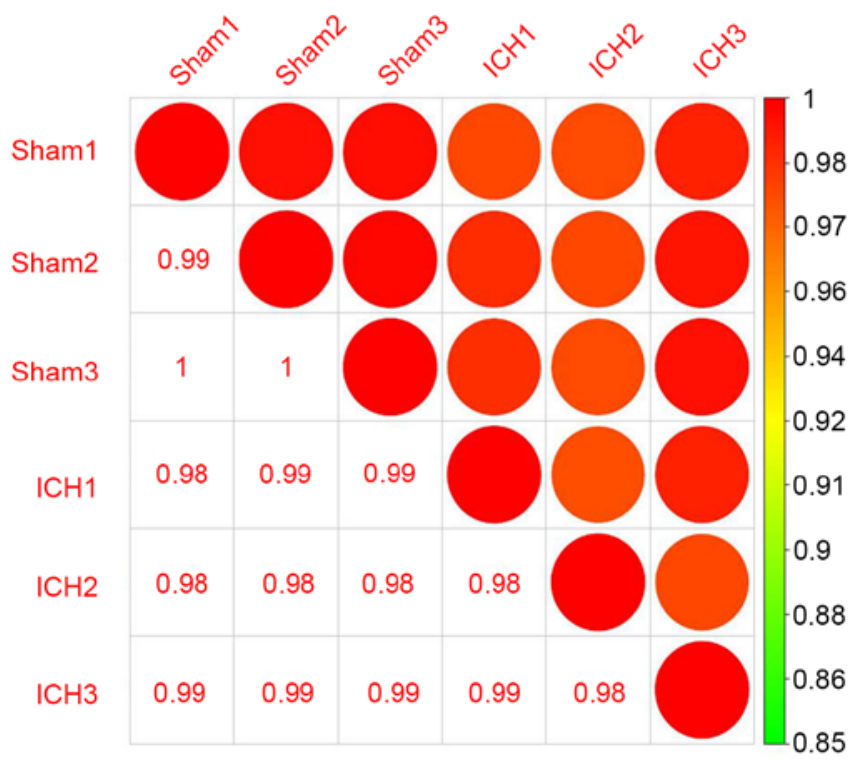

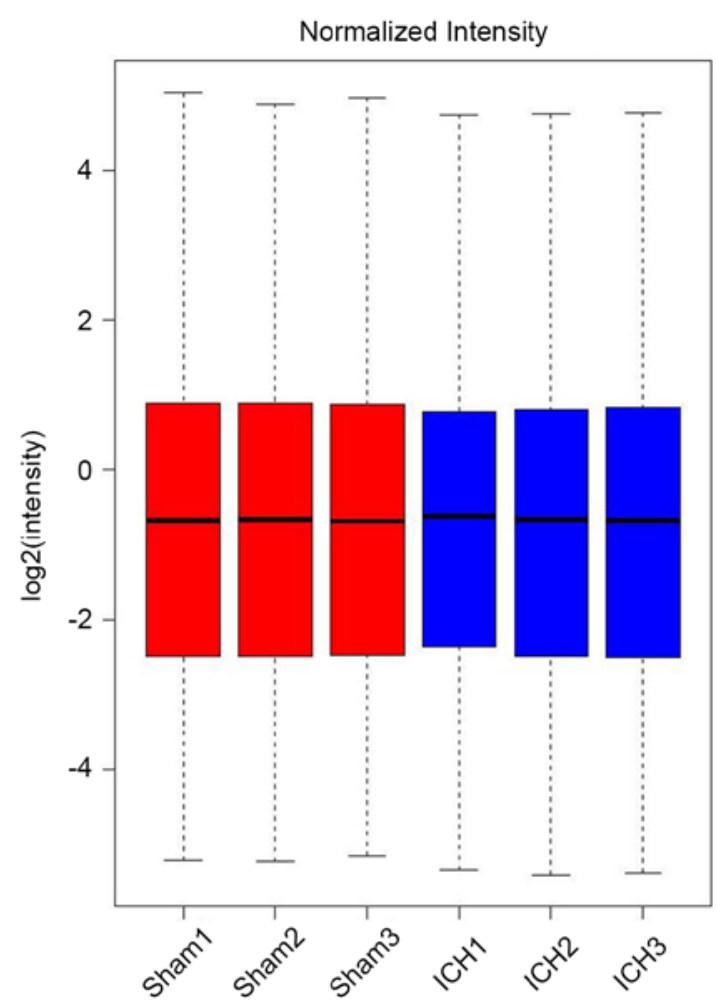

C

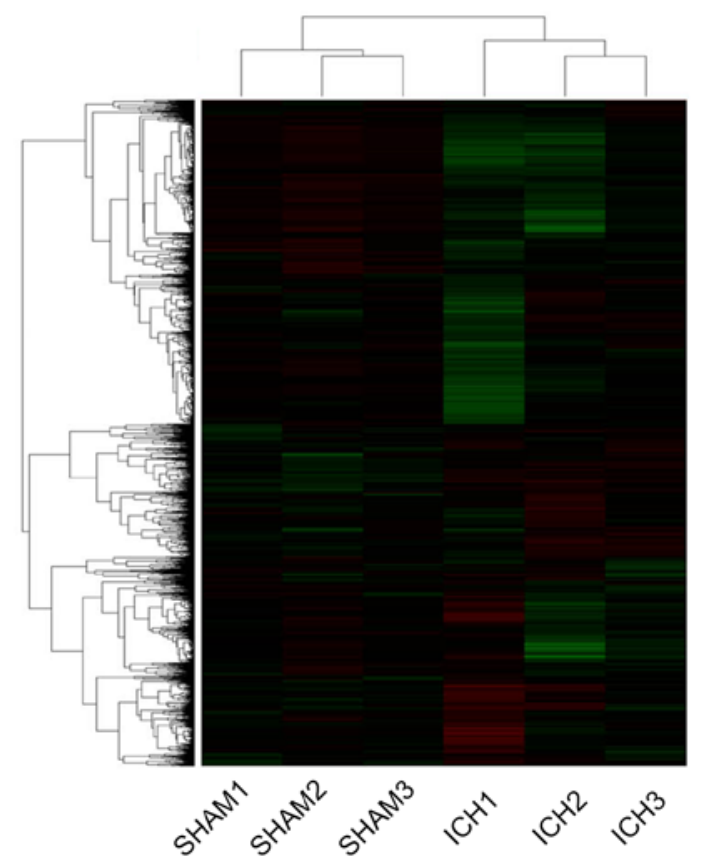

Figure 3. Detection of gene expression profile in perihematoma following ICH. (A) Pearson's correlation coefficient for the comparison between gene expression variation in the sham (red) and perihematoma post-ICH (blue). (B) Correlation coefficient (the degree of correlation) of samples. Color represents the degree of correlation. (C) Raw data clustering performance (red, high expression; green, low expression). ICH, intracerebral hemorrhage.

ID of these genes. Functional classification of differentially expressed genes was performed using Gene Ontology (GO) and Pathways (IPA) analyses. A link diagram of the pictorial information transmission path was constructed using the Kyoto Encyclopedia of Genes and Genomes (KEGG) database. Differentially expressed genes associated with neurological disease were screened for ICH. IPA was used to analyze differences in genes. PANTHER (the Protein Annotation Through Evolutionary Relationship) was used to analyze differentially expressed genes. Venny 2.1.0 software was used to compare the 15 selected differentially expressed genes. 
A

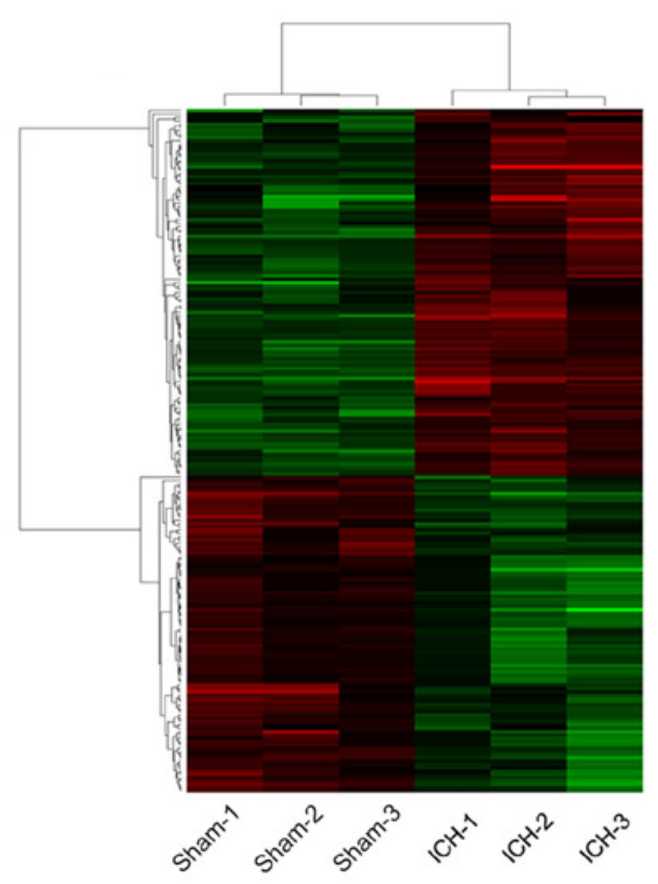

C

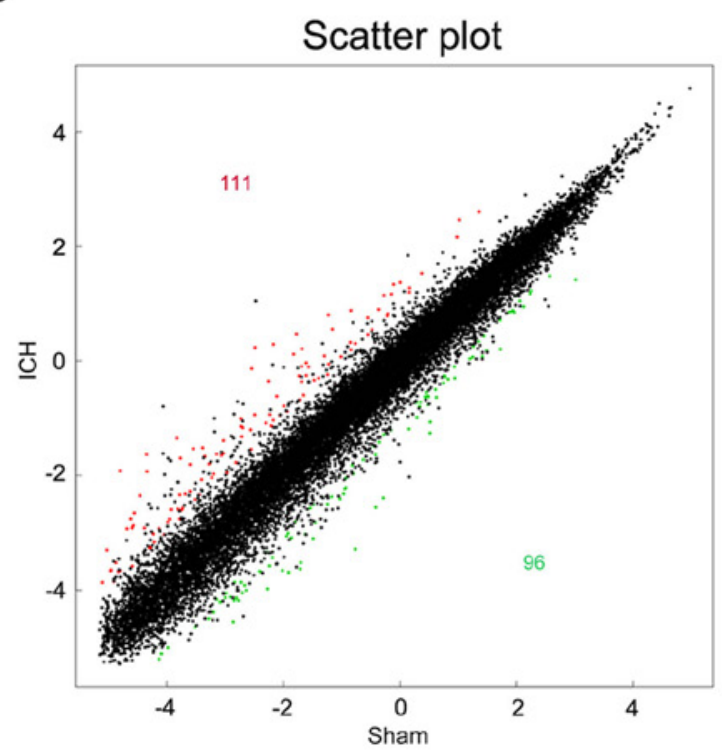

B

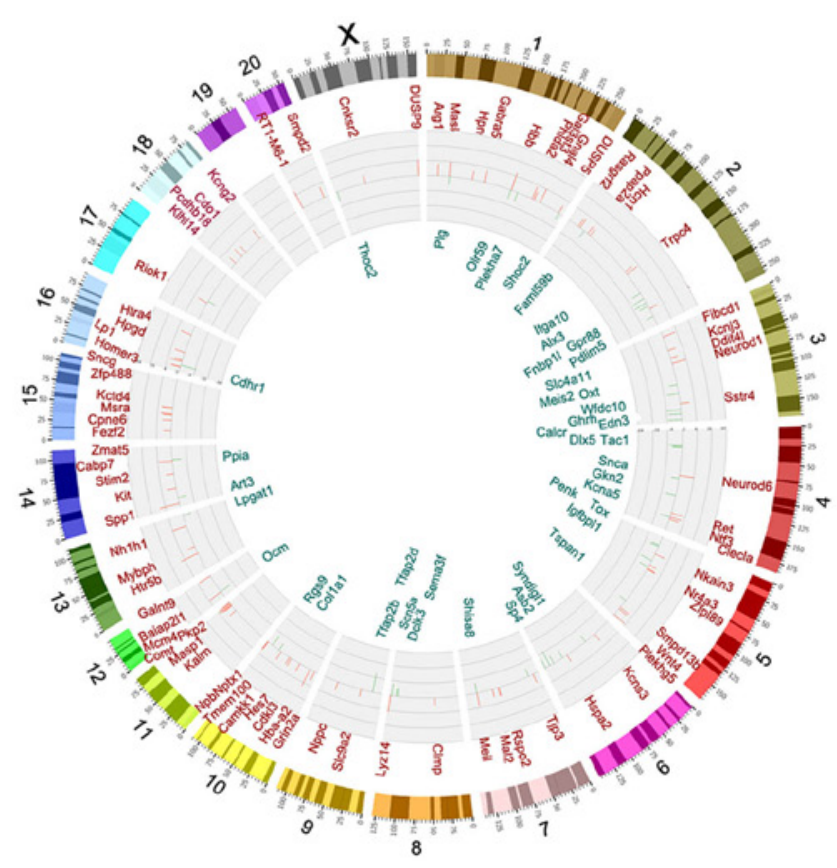

D

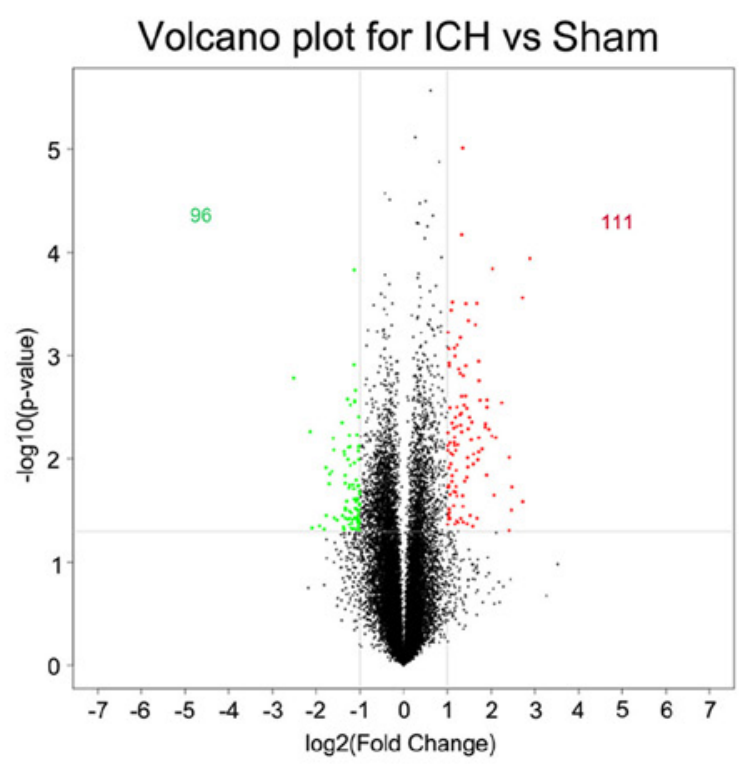

Figure 4. Cluster analysis was performed on 120 differentially expressed genes. (A) Clustering, (B) Circos, (C) scatter and (D) volcano diagram of differentially expressed genes in the sham and ICH groups. Red, upregulation; green, downregulation; black, non-differentially expressed. ICH, intracerebral hemorrhage.

Reverse transcription-quantitative $(R T-q) P C R$. The sequences of the primers used in the present analysis are shown in Table I. For tissue total RNA extraction, the brain tissue surrounding the frozen hematoma (distance, $3 \mathrm{~mm}$ ) was extracted and weighed, placed into a $1.5 \mathrm{ml}$ RNase-free EP tube and $1 \mathrm{ml}$ TRIzol ${ }^{\circledR}$ (Invitrogen; Thermo Fisher Scientific, Inc.) was added to the homogenizer for homogenization on ice. The process was allowed to proceed at a low temperature, and the tissue was left on ice for $30 \mathrm{~min}$ for lysis. Chloroform $(200 \mu \mathrm{l})$ was added, and the tissue was shaken for $15 \mathrm{sec}$, before being allowed to stand at room temperature for $2 \mathrm{~min}$. Centrifugation was performed at $13,000 \mathrm{x}$ g at $4^{\circ} \mathrm{C}$ for $15 \mathrm{~min}$. Supernatant $(300 \mu \mathrm{l})$ was separated and an equal volume of isopropanol $(300 \mu \mathrm{l})$ was added, before the mixture was allowed to rest for 10 min following gentle mixing. The tissue was centrifuged at $13,000 \mathrm{x}$ g at $4^{\circ} \mathrm{C}$ for $10 \mathrm{~min}$, and the supernatant was then carefully discarded. The precipitate was carefully washed with $1 \mathrm{ml}$ RNase-free $75 \%$ ethanol, and centrifuged again at $13,000 \mathrm{x} \mathrm{g}$ at $4^{\circ} \mathrm{C}$ for $15 \mathrm{~min}$. After drying the precipitate, diethylpyrocarbonate-treated water $(40 \mu \mathrm{l})$ was added to promote dissolution at $65^{\circ} \mathrm{C}$ for $10-15 \mathrm{~min}$. The optical density value and concentration of RNA were measured. RNA was stored at $-80^{\circ} \mathrm{C}$ for later use. 
A

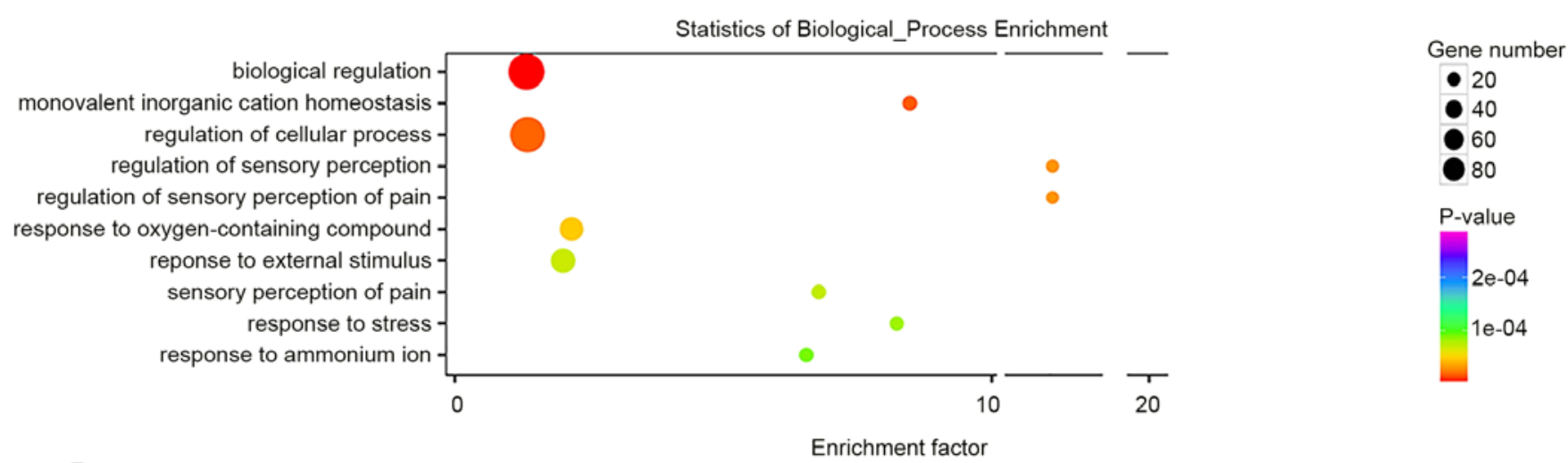

B

Enrichment factor

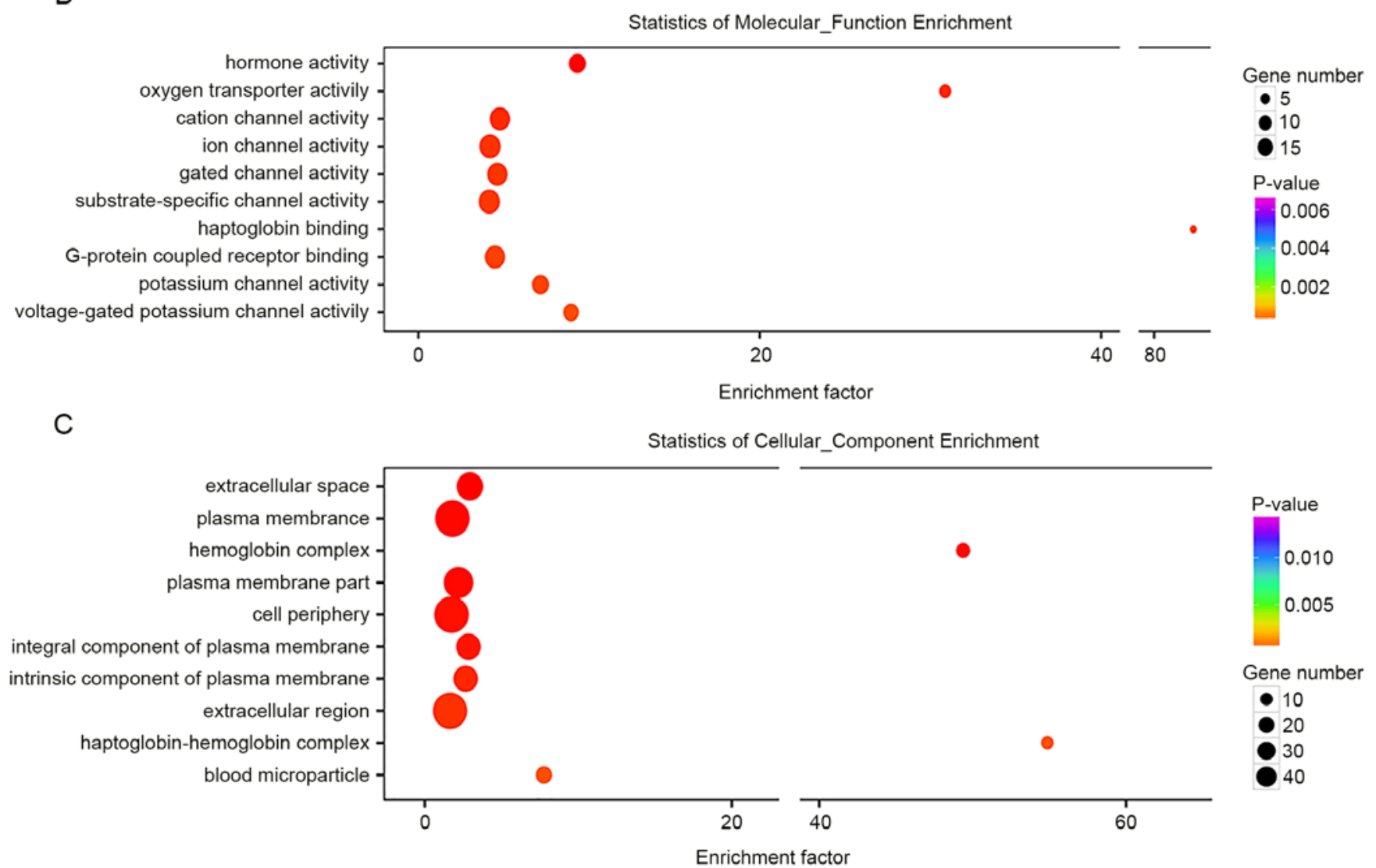

Figure 5. Gene Ontology functional annotation of differentially expressed genes. The top 10 annotations with the most significance are listed according to P-value. (A) Biological process, (B) molecular function and (C) cell component annotations of differentially expressed genes between the intracerebral hemorrhage and sham groups.

A HisScript ${ }^{\circledR}$ II First Strand cDNA Synthesis kit $(+\mathrm{gDNA}$ wiper) was used to reverse transcribe 500 ng RNA into complementary (c)DNA on ice. The cDNA obtained by reverse transcription was subjected to RT-qPCR in accordance with the instructions of the AceQ ${ }^{\circledR}$ qPCR SYBR ${ }^{\circledR}$ Green Master Mix kit (Vazyme Biotech Co., Ltd.).

Multiple wells in triplicate were set up for each PCR reaction. After the amplification program, the dissolution and amplification curves were analyzed and the maximum-error term was excluded. The thermocycling conditions are shown in Table II. The PCR yield was calculated using the $2^{-\Delta \Delta \mathrm{Cq}}$ method (21). The internal reference was $\beta$-actin.
Hematoxylin and eosin $(H \& E)$ staining. Histopathologic changes of the perihematoma in the striatum area were studied using H\&E (Beyotime Institute of Biotechnology) staining in rats at 2 and 7 days post- $\mathrm{ICH}$. Following fixation in $4 \%$ paraformaldehyde at $4^{\circ} \mathrm{C}$ for $12 \mathrm{~h}$, the sections $(5 \mu \mathrm{m})$ were stained in hematoxylin solution for $30 \mathrm{sec}$ and eosin solution for $1 \mathrm{~min}$ at room temperature. Following gradient dehydration, the slides were further cleared with xylene and coverslipped with neutral gum.

Statistical analysis. All data are expressed as the mean \pm SD. Each experiment was repeated six times. Pairwise comparisons were performed using unpaired Student's t test and one-way ANOVA 
A
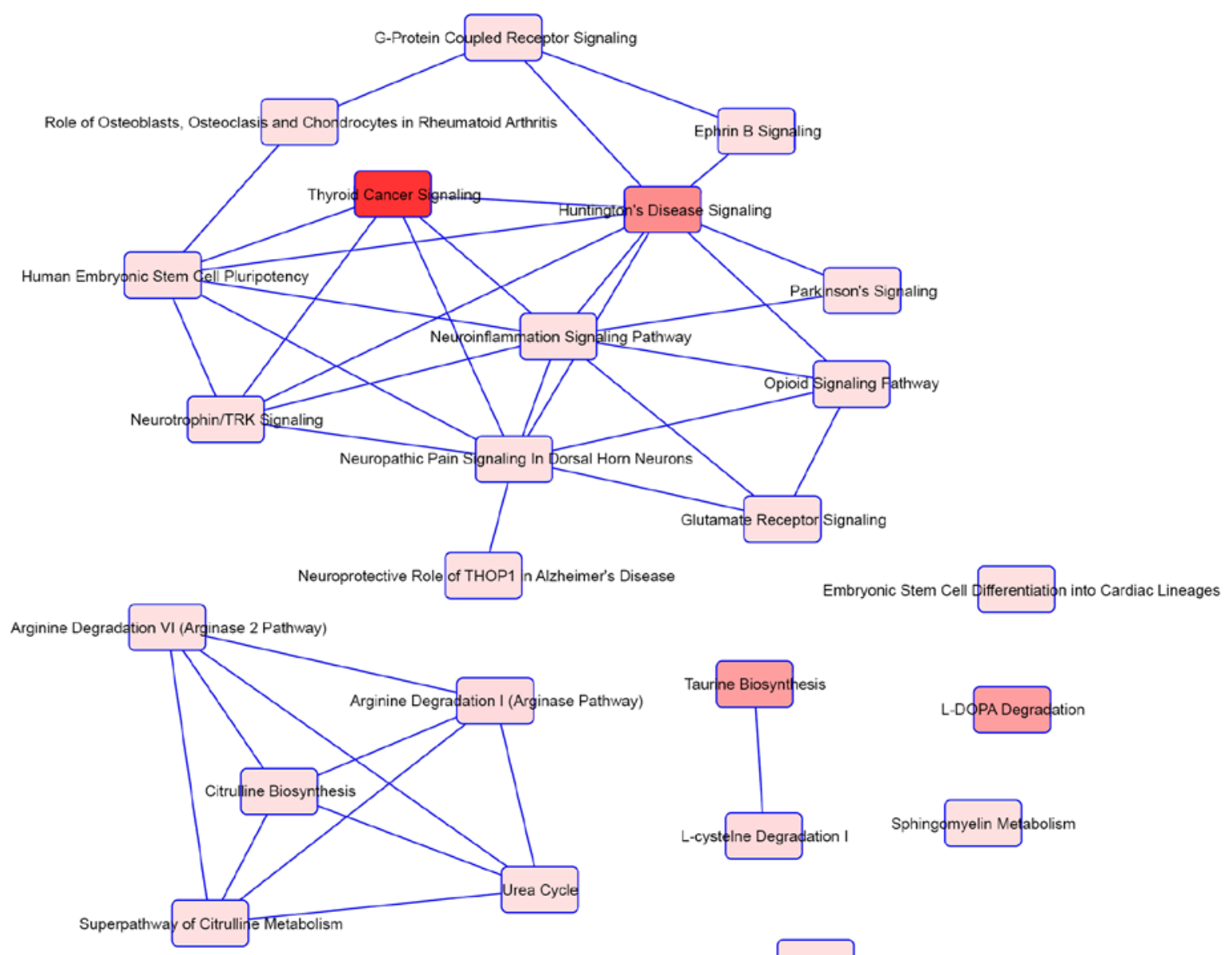

Hematopoiesis from Multipptent Stem Cells
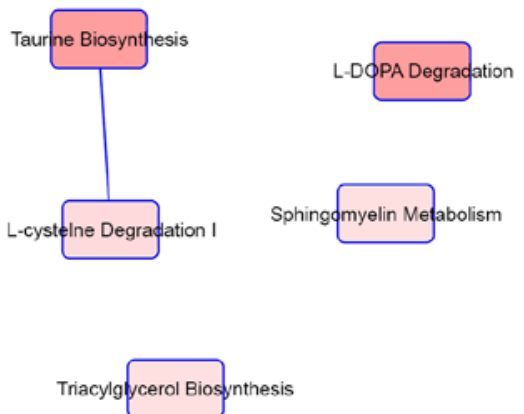

B

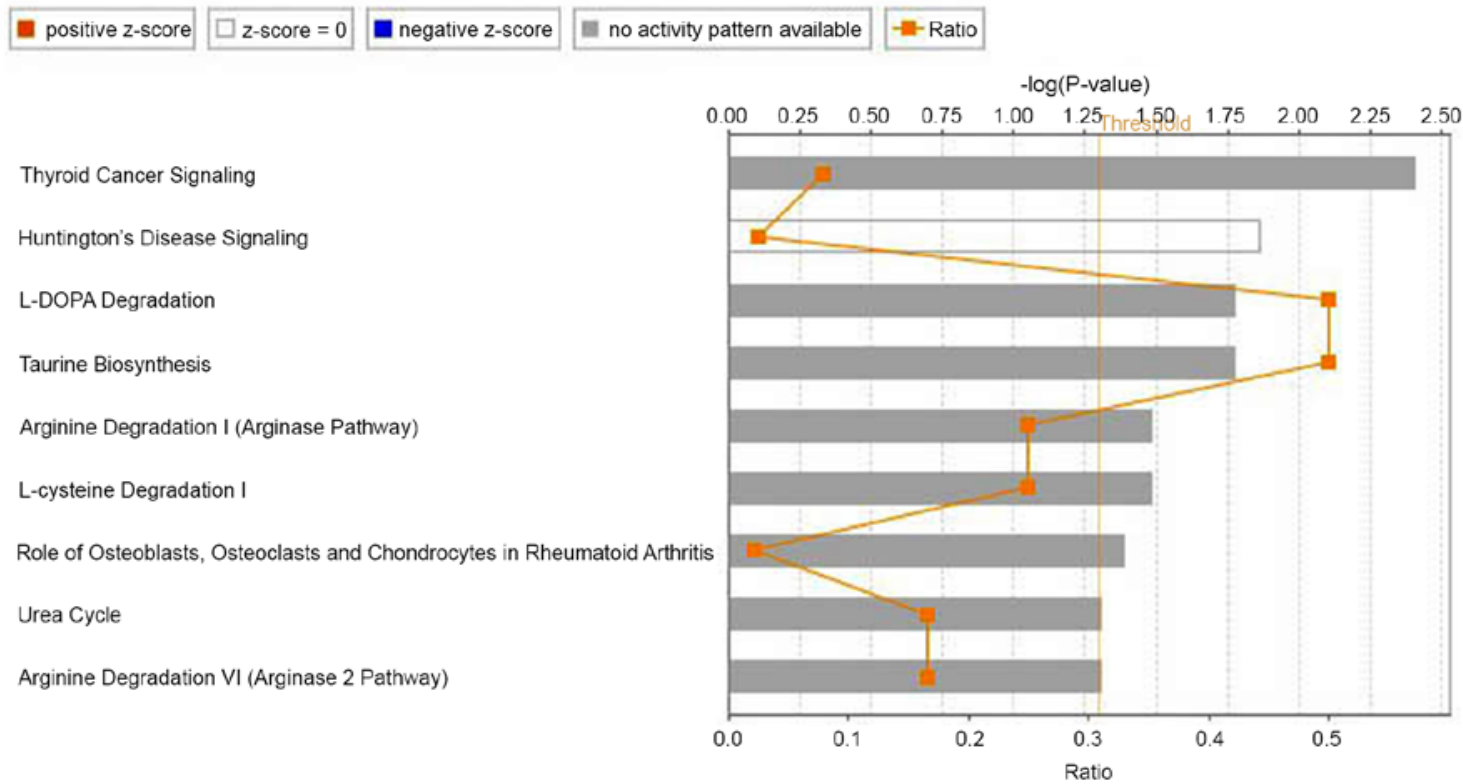

Figure 6. Continued.

was conducted for comparisons among multiple groups, followed by post hoc Bonferroni's correction. All statistical analyses were performed using SPSS version 15.0 software (SPSS, Inc.). Pearson correlation coefficient analysis was used to compare different samples. Circos (http://circos.ca/) was used for plotting. P $<0.05$ was considered to indicate a statistically significant difference. 

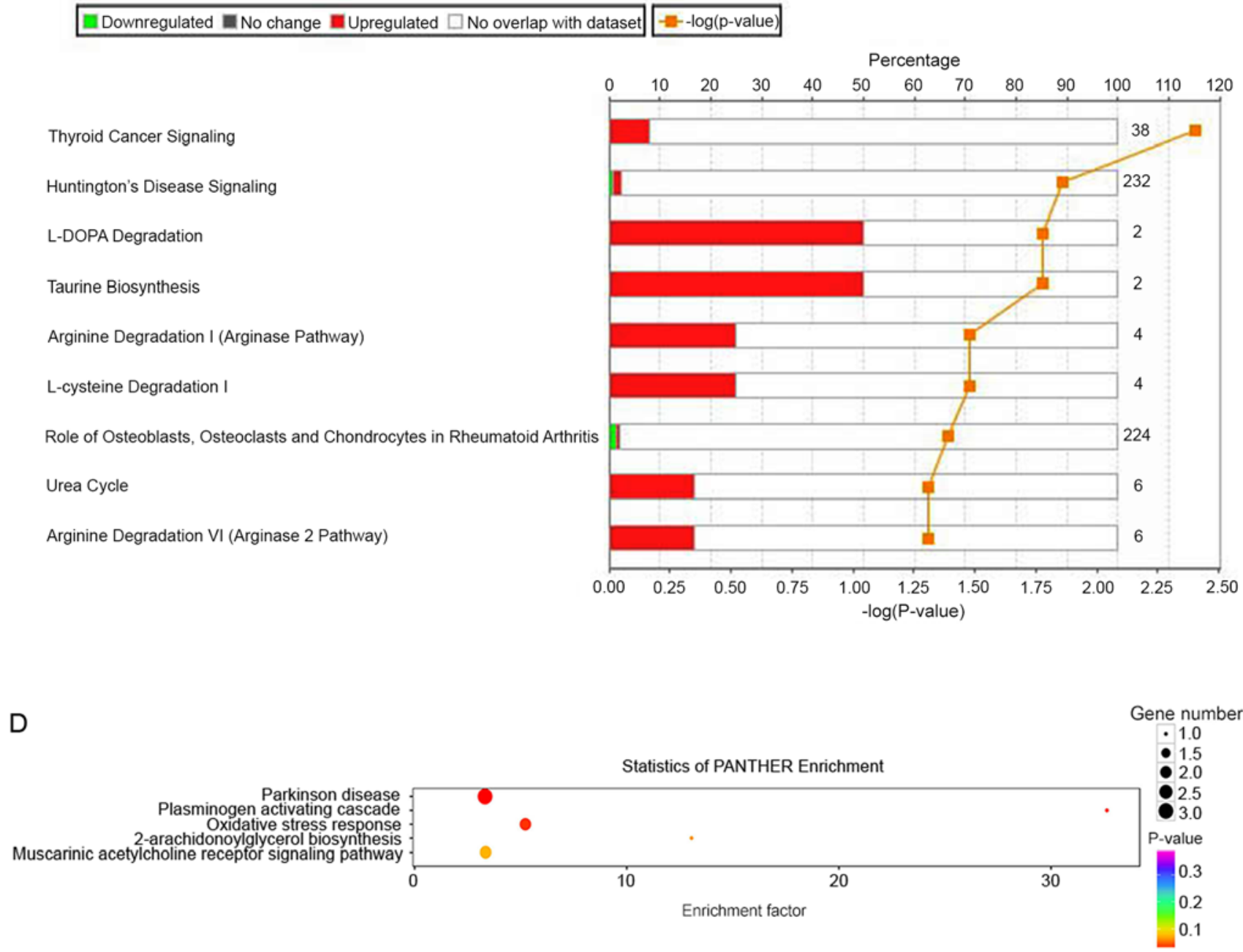

Figure 6. Classical signal pathway analysis of differentially expressed genes. (A) Classical signaling pathways associated with the differentially expressed genes. The darker the color, the greater the number of differentially expressed genes. (B) Differences in these classical signal pathways are ranked by significance. (C) Differentially expressed genes in the top 9 classical signaling pathways with significant differences. (D) Enrichment of the PANTHER signaling pathway and the top 5 genes with different gene expression profiles enriched in the PANTHER pathway. PANTHER, Protein Annotation Through Evolutionary Association.

\section{Results}

Changes in neuronal function and pathological changes in rats following $\mathrm{ICH}$. In a previous study, it had been demonstrated that ICH peaks at day 2 post-surgery (20). Forelimb placement and corner turn tests were used in the present study to determine the success of the ICH model. Neurological dysfunction was most severe at $6 \mathrm{~h}$ post-ICH, before improving (Fig. 1A and B). At day 7 post-ICH, there was still a significant difference in neurological function of the ICH-induced rats compared with the sham group. The graph shows differences were significant throughout the entire period. This demonstrated that the ICH model had been constructed successfully. Since the death of neurons in the peripheral hematoma region following ICH causes severe functional impairment, levels of caspase- 3 and cleaved caspase- 3 were examined as indicators of neuronal apoptosis in the peripheral hematoma region (22). Expression of cleaved caspase-3 in the sham group was low, although the expression level increased following $\mathrm{ICH}$, reaching a peak on day 2 post- $\mathrm{ICH}$, before the expression levels were downregulated (Fig. 2). Compared with the sham group (2C-F), the levels of cleaved caspase- 3 in the peripheral hematoma region at 2 days post-ICH were markedly high (Fig. 2G-J). Additionally, elevated levels of cleaved caspase-3 were primarily co-located with the neurons, which confirmed that the increase in activation of cleaved caspase- 3 in the peripheral hematoma region was primarily associated with the apoptosis of neurons (Fig. 2G-J). At 2 days post-ICH in rats, the hematoma was elliptic, and there was also clear edema of surrounding tissue, as shown by H\&E staining (Fig. S1). This also revealed that the severest stage of neurological impairment occurred on day 2 post-ICH.

Detection of gene expression profile in perihematoma tissue following ICH in rats. In order to investigate the molecular mechanism of the perihematoma microenvironment following 
Table III. Classical signaling pathways of enriched gene expression profiles in perihematoma following ICH.

\begin{tabular}{lcc}
\hline Pathway & Overlap & Genes \\
\hline 'Thyroid cancer signaling' & $3 / 38$ & NTF3, BDNF, RET \\
'Huntington's disease signaling' & $6 / 232$ & NEUROD1, BDNF, PENK, \\
& & GNA14, SNCA, HSPA2 \\
'L-DOPA degradation' & $1 / 2$ & COMT \\
'Taurine biosynthesis' & $1 / 2$ & CDO1 \\
'Arginine degradation I (arginase pathway)' & $1 / 4$ & ARG1 \\
'L-cysteine degradation I' & $1 / 4$ & CDO1 \\
'Role of osteoblasts, osteoclasts and chondrocytes in rheumatoid arthritis' & $5 / 224$ & COL1A1, SPP1, DLX5, \\
'Urea cycle' & & CALCR, WNT4 \\
'Arginine degradation VI (arginase 2 pathway)' & $1 / 6$ & ARG1 \\
\end{tabular}

NTF3, neurotrophin 3; BDNF, brain-derived neurotrophic factor; RET, ret proto-oncogene; NEUROD1, neuronal differentiation 1; PENK, proenkephalin; GNA14, G protein subunit $\alpha 14$; SNCA, synuclein $\alpha$; HSPA2, heat shock protein family A (Hsp70) member 2; COMT, catechol-o-methyltransferase; CDO1, cysteine dioxygenase type 1; COL1A1, collagen type I $\alpha 1$ chain; SPP1, secreted phosphoprotein 1; DLX5, distal-less homeobox 5; CALCR, calcitonin receptor; WNT4, wnt family member 4; ARG1, arginase 1.

Table IV. Expression profile differential genes and disease pathway functional enrichment.

\begin{tabular}{llll}
\hline ID & \multicolumn{1}{c}{ Associated network function } & Score \\
\hline 1 & 'Nervous system development and function', 'psychological disorders', 'organismal injury and abnormalities' & 45 \\
2 & 'Cellular development', 'embryonic development', 'nervous system development and function' & 37 \\
3 & 'Cellular assembly and organization', 'cellular function and maintenance', 'developmental disorder' & 28 \\
4 & 'Cardiovascular disease', 'nervous system development and function', 'neurological disease' & 26 \\
5 & 'Cancer', 'gastrointestinal disease', 'organismal injury and abnormalities' & 21 \\
\hline
\end{tabular}

$\mathrm{ICH}$, microarray detection of the gene expression profile was performed 1 day post-ICH (Agilent; 8x60 K, single channel). From the results of the Pearson correlation coefficient analysis, comparisons of samples between the sham and ICH groups exhibited differences, whereas samples derived from the same group were similar (Fig. 3A). The boxplot presents the expression level of the whole gene (probe) before and after normalization of different samples; expression levels tended to be similar between samples within each group (Fig. 3B). Original data clustering identified differentially expressed genes between the sham and ICH group, including 210 up- and 173 downregulated genes; a further 24,150 genes were not significantly differentially expressed (Fig. 3C).

Changes in gene expression profile in perihematoma tissue following ICH. In order to analyze the significance of the microarray expression profile data, data with an original $\log 2$ signal value $<120$ were filtered out; the resulting number of differentially expressed genes in the perihematoma tissue following ICH was decreased to 207, among which 111 genes were up- and 96 were downregulated (Fig. 4A). A Circos plot was constructed to show the specific positions of differentially expressed genes on the chromosome (Fig. 4B). Differential variations in the gene expression of samples were compared between the sham and the ICH groups (Fig. 4C and D).
Genome annotation. The different gene spectra were classified according to GO by GSEA. Three domains were included in the GO analysis: Biological process, cell component and molecular function. The top 10 most significant annotations were listed according to P-value. Differentially expressed genes were primarily associated with 'biological regulation', 'monovalent inorganic cation homeostasis', 'regulation of cellular processes', 'regulation of pain sensation', 'response to external stimulation' and 'response to stress' (Fig. 5A). Differentially expressed genes were also associated with 'hormone activity', 'oxygen transporter activity' and activation of a series of ion channels (Fig. 5B). Localization of differentially expressed genes occurred in the 'extracellular space' and 'plasma membrane' (Fig. 5C). In combination with GO analysis, changes in the gene expression profile in the peripheral hematoma region following ICH were analyzed; these were primarily associated with the harmful/beneficial effects of external stimulation received by neurons in the peripheral hematoma region via activating ion channels (receptors) on the cell membrane and regulating the intracellular biological (stress) process.

Classical signal path analysis. The study of classical signaling pathways involved in differentially expressed genes serves an important role in understanding the pathology and 


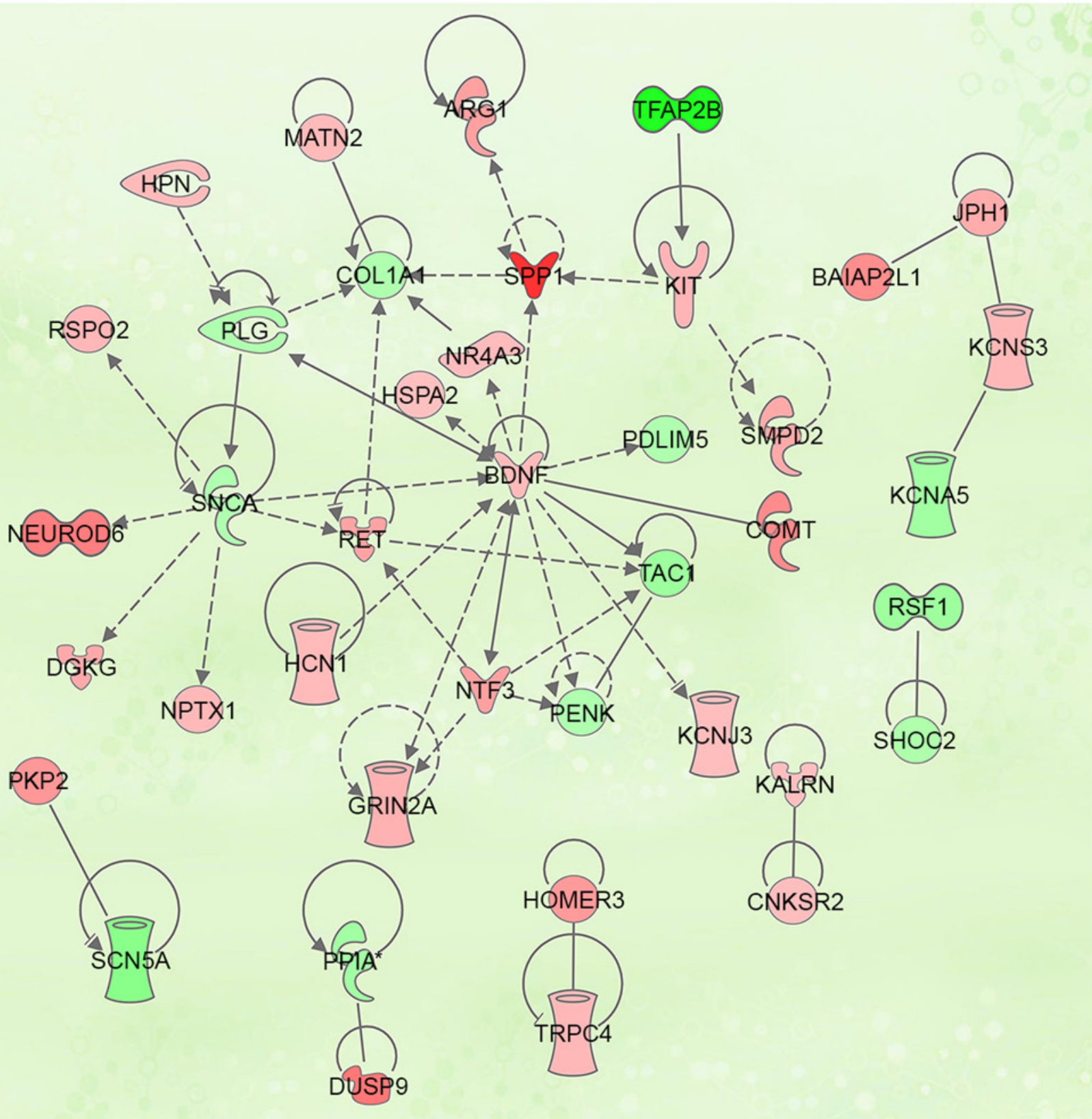

Figure 7. Protein interaction network. Ingenuity Pathway Analysis software was used to analyze the protein interaction network of different genes in rat microarray expression profile. Red, upregulated; green, downregulated.

underlying molecular mechanism of the peripheral hematoma following ICH. Using Ingenuity Pathway Analysis (IPA, digitalinsights.qiagen.com/products-overview/discovery-insightsportfolio/analysis-and-visualization/qiagen-ipa/), a path analysis software, group differences (differences in genes) around the hematoma following ICH were studied using classic genetic spectrum signal-pathway enrichment analysis. The results revealed that 25 classical pathways were potentially enriched by changes in gene expression profile in the peripheral hematoma region following ICH (Fig. 6A). According to the $\mathrm{z}$-score, the 9 most significant enrichment pathways were isolated (Fig. 6B and C; Table III). Z-score $\geq 2$ or $\leq-2$ was used to represent activation or inhibition of the signaling pathway, respectively; z-scores obtained did not show activation or inhibition of the signaling pathways. In addition, the Protein
Annotation Through Evolutionary Relationship (PANTHER) pathway database analysis indicated that the differentially expressed genes in the peripheral hematoma region following ICH may be associated with 'oxidative stress response' (Fig. 6D).

Association between differentially expressed gene profiles and disease pathways. According to the changes in gene expression profile in the peripheral hematoma region following $\mathrm{ICH}$ and the enrichment of disease pathways, five disease pathways were identified that had the closest association with changes in gene expression profile in the peripheral hematoma region following ICH, according to the z-score analysis (Table IV). Functions associated with the neuropathology of the peripheral hematoma following ICH were further analyzed, including 
Table V. Protein interaction network protein.

\begin{tabular}{|c|c|c|c|c|c|}
\hline ID & Probe name & P-value & Fold-change (absolute value) & UniGene ID & Gene symbol \\
\hline 1 & A_42_P758222 $2^{\mathrm{a}}$ & 0.008947 & 3.019220 & Rn.9857 & ARG1 \\
\hline 2 & A_64_P035936 ${ }^{\mathrm{a}}$ & 0.004929 & 3.643115 & Rn.21473 & BAIAP2L1 \\
\hline 3 & A_44_P437896 ${ }^{\mathrm{a}}$ & 0.028281 & 2.204321 & Rn.11266 & BDNF \\
\hline 4 & A_44_P178576 ${ }^{\mathrm{a}}$ & 0.022114 & 2.085212 & Rn.42893 & CNKSR2 \\
\hline 5 & A_64_P040278 & 0.003882 & -2.030321 & Rn.2953 & COL1A1 \\
\hline 6 & A_64_P038419a & 0.014364 & 3.714765 & Rn.220 & COMT \\
\hline 7 & A_44_P179145 & 0.003238 & 2.717895 & Rn.10544 & DGKG \\
\hline 8 & A_44_P192406 ${ }^{\mathrm{a}}$ & 0.006205 & 4.322715 & Rn.100548 & DUSP9 \\
\hline 9 & A_44_P505902 ${ }^{\mathrm{a}}$ & 0.001482 & 2.461507 & Rn.9710 & GRIN2A \\
\hline 10 & A_44_P1053605 & 0.020786 & 2.206627 & Rn.21408 & HCN1 \\
\hline 11 & A_44_P463822 & 0.000312 & 3.201671 & Rn.144573 & HOMER3 \\
\hline 12 & A_64_P134748 & 0.000838 & 2.225321 & Rn.11139 & $\mathrm{HPN}$ \\
\hline 13 & A_44_P309081 ${ }^{\mathrm{a}}$ & 0.008181 & 2.012769 & Rn.211303 & HSPA2 \\
\hline 14 & A_44_P116510 & 0.017897 & 2.037972 & Rn.87882 & KALRN \\
\hline 15 & A_44_P383960 & 0.005883 & -2.374771 & Rn.162789 & KCNA5 \\
\hline 16 & A_44_P452282 & 0.037462 & 2.078167 & Rn.9809 & $\mathrm{KCNJ} 3$ \\
\hline 17 & A_44_P416938 & 0.020996 & 2.285903 & Rn.10878 & KCNS3 \\
\hline 18 & A_64_P117011ª & 0.007250 & 2.368849 & Rn.54004 & KIT \\
\hline 19 & A_64_P133152 & 0.000144 & 4.090774 & Rn.84947 & NEUROD6 \\
\hline 20 & A_44_P260751 & 0.007369 & 2.235491 & Rn.54707 & NPTX1 \\
\hline 21 & A_43_P12619a & 0.016427 & 2.141300 & Rn.62694 & NR4A3 \\
\hline 22 & A_44_P496447ª & 0.011159 & 3.004565 & Rn.9715 & NTF3 \\
\hline 23 & A_43_P12767 b & 0.007438 & -2.014961 & Rn.221146 & PDLIM5 \\
\hline 24 & A_42_P749184 ${ }^{\mathrm{b}}$ & 0.041926 & -2.026286 & Rn.10015 & PENK \\
\hline 25 & A_44_P999507ª & 0.001125 & 3.296893 & Rn.27944 & PKP2 \\
\hline 26 & A_42_P599062 & 0.010107 & -2.032312 & Rn.20178 & PLG \\
\hline 27 & A_64_P016970 & 0.037218 & -2.35685 & Rn.1463 & PPIA \\
\hline 28 & A_64_P154019a & 0.006528 & 2.909228 & Rn.93200 & RET \\
\hline 29 & A_64_P082924 ${ }^{\mathrm{a}}$ & 0.039384 & 2.310934 & Rn.225158 & RSPO2 \\
\hline 30 & A_44_P823749 b & 0.037002 & -3.006713 & Rn.32074 & SCN5A \\
\hline 31 & A_44_P356962 & 0.007621 & -2.042897 & Rn.156055 & SHOC2 \\
\hline 32 & A_44_P265965 & 0.015076 & 2.715601 & Rn.18572 & SMPD2 \\
\hline 33 & A_64_P160635 & 0.020375 & -2.012871 & Rn.1827 & SNCA \\
\hline 34 & A_44_P491796 & 0.025735 & 6.590008 & Rn.8871 & SPP1 \\
\hline 35 & A_64_P009999 & 0.037288 & -2.521888 & Rn.1920 & TAC1 \\
\hline 36 & A_43_P18397' & 0.001637 & -5.744454 & Rn.12263 & TFAP2B \\
\hline 37 & A_64_P093467 & 0.003924 & 2.266533 & Rn.10853 & TRPC4 \\
\hline
\end{tabular}

Protein interaction network analysis was performed on the genes with different expression profiles. ${ }^{\mathrm{a}}$ Upregulated. ${ }^{\mathrm{b}}$ Downregulated. ARG1, arginase 1; BAIAP2L1, BAR/IMD domain containing adaptor protein 2 like 1; BDNF, brain-derived neurotrophic factor; CNKSR2, connector enhancer of kinase suppressor of ras 2; TFAP2B, transcription factor AP-2 $\beta$; SNCA, synuclein $\alpha$; PPIA, peptidylprolyl isomerase A; SHOC2, SHOC2 leucine rich repeat scaffold protein; COMT, catechol-o-methyltransferase; COL1A1, collagen type I $\alpha 1$ chain; SPP1, secreted phosphoprotein 1; DGKG, diacylglycerol kinase $\gamma$; DUSP9, dual specificity phosphatase 9; PKP2, plakophilin 2; HOMER3, homer scaffold protein 3; KALRN, kalirin rhoGEF kinase; GRIN2A, glutamate ionotropic receptor NMDA type subunit 2A; HCN1, hyperpolarizationactivated cyclic nucleotide gated potassium channel 1; HPN, hepsin; HSPA2, heat shock protein family A member; KCNA5, potassium voltage-gated channel subfamily A member 5 ; KCNJ3, potassium inwardly rectifying channel subfamily J member 3; KCNS3, potassium voltage-gated channel modifier subfamily S member 3; KIT, kit proto-oncogene; NEUROD6, neuronal differentiation 6; NPTX1, neuronal pentraxin 1; NR4A3, nuclear receptor subfamily 4 group A member 3; NTF3, neurotrophin 3; PDLIM5, PDZ and LIM domain 5; PENK, proenkephalin; PLG, plasminogen; RET, ret proto-oncogene; RSPO2, R-spondin 2; SCN5A, sodium voltage-gated channel $\alpha$ subunit 5; SMPD2, sphingomyelin phosphodiesterase 2; TAC1, tachykinin precursor 1; TRPC4, transient receptor potential cation channel subfamily $\mathrm{C}$ member 4 .

'development of nervous system and neurological diseases', 'nervous system development and function', 'cellular structure, function and developmental disease', 'nervous system disorder' and 'organismal injury and abnormalities'. 
Table VI. Types of differentially expressed gene.

Family

Gene

Enzyme

Cytokines

Growth factor

Transcription factor

Ion channel

Transmembrane and nuclear receptors

Other

\author{
$\mathrm{ARG1}^{\mathrm{a}}, \mathrm{SMPD}^{\mathrm{a}}, \mathrm{COMT}^{\mathrm{a}}, \mathrm{SNCA}^{\mathrm{b}}, \mathrm{PPIA}^{\mathrm{b}}, \mathrm{PLG}^{\mathrm{b}}, \mathrm{DGKG}^{\mathrm{a}}, \mathrm{RET}^{\mathrm{a}}$, \\ KALRN $^{\mathrm{a}}$, DUSP9 ${ }^{\mathrm{a}}, \mathrm{HPN}^{\mathrm{a}}$ \\ SPP1 ${ }^{\text {a }}$ \\ $\mathrm{NTF}^{\mathrm{a}}, \mathrm{BDNF}^{\mathrm{a}}$

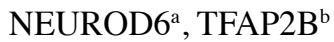 \\ $\mathrm{HCN}^{\mathrm{a}}, \mathrm{GRIN} \mathrm{A}^{\mathrm{a}}, \mathrm{SCN}^{\mathrm{a}} \mathrm{A}^{\mathrm{b}}, \mathrm{KCNJ}^{\mathrm{a}}, \mathrm{KCNS}^{\mathrm{a}}{ }^{\mathrm{T}}, \mathrm{TRPC}^{\mathrm{a}}, \mathrm{KCNA}^{\mathrm{b}}$ \\ $\mathrm{KIT}^{\mathrm{a}}$, NR4A3 ${ }^{\mathrm{a}}$ \\ BAIAP2L1 $1^{\text {a }}, \mathrm{COL}_{1 \mathrm{~A}} 1^{\mathrm{b}}, \mathrm{HSPA}^{\mathrm{a}}, \mathrm{PDLIM}^{\mathrm{b}}, \mathrm{TAC}^{\mathrm{b}}, \mathrm{PENK}^{\mathrm{b}}$, \\ $\mathrm{NPTX}^{\mathrm{a}}, \mathrm{PKP}^{\mathrm{a}}, \mathrm{RSPO}^{\mathrm{a}}$, $\mathrm{SHOC} 2^{\mathrm{b}}, \mathrm{HOMER}^{\mathrm{a}}, \mathrm{CNKSR} 2^{\mathrm{a}}$
}

\begin{abstract}
${ }^{a}$ Upregulated. ${ }^{b}$ Downregulated. ARG1, arginase 1; SMPD2, sphingomyelin phosphodiesterase 2; COMT, catechol-o-methyltransferase; SNCA, synuclein alpha; PPIA, peptidylprolyl isomerase A; PLG, plasminogen; DGKG, diacylglycerol kinase gamma; RET, ret proto-oncogene; KALRN, kalirin rhoGEF kinase; DUSP9, dual specificity phosphatase 9; HPN, hepsin; SPP1, secreted phosphoprotein 1; NTF3, neurotrophin 3; BDNF, brain-derived neurotrophic factor; NEUROD6, neuronal differentiation 6; TFAP2B, transcription factor AP-2 $\beta$; HCN1, hyperpolarization activated cyclic nucleotide gated potassium channel 1; GRIN2A, glutamate ionotropic receptor NMDA type subunit 2A; SCN5A, sodium voltage-gated channel $\alpha$ subunit 5; KCNJ3, potassium inwardly rectifying channel subfamily J member 3; KCNS3, potassium voltage-gated channel modifier subfamily S member 3; TRPC4, transient receptor potential cation channel subfamily C member 4; KCNA5, potassium voltage-gated channel subfamily A member 5; KIT, kit proto-oncogene; NR4A3, nuclear receptor subfamily 4 group A member 3; BAIAP2L1, BAR/IMD domain containing adaptor protein 2 like 1; COL1A1, Collagen type I $\alpha 1$ chain; HSPA2, heat shock protein family A (Hsp70) member 2; PDLIM5, PDZ and LIM domain 5; TAC1, tachykinin precursor 1; PENK, proenkephalin; NPTX1, neuronal pentraxin 1; PKP2, plakophilin 2; RSPO2, r-spondin 2; SHOC2, SHOC2 leucine rich repeat scaffold protein; HOMER3, homer scaffold protein 3; CNKSR2, connector enhancer of kinase suppressor of ras 2.
\end{abstract}

Table VII. Localization of differentially expressed genes.

\begin{tabular}{|c|c|}
\hline Location & Gene \\
\hline Extracellular space & $\mathrm{SPP} 1^{\mathrm{a}}$ \\
\hline Plasma membrane & $\begin{array}{l}\mathrm{CNKSR}^{\mathrm{a}}, \mathrm{HOMER}^{\mathrm{a}}, \mathrm{HPN}^{\mathrm{a}}, \mathrm{KIT}^{\mathrm{a}} \text {, } \\
\mathrm{PKP}^{\mathrm{a}}{ }^{\mathrm{a}}, \mathrm{RET}^{\mathrm{a}}\end{array}$ \\
\hline Cytoplasm & $\begin{array}{l}\text { BAIAP2L1 }^{\mathrm{a}}, \mathrm{COMT}^{\mathrm{a}}, \mathrm{KALRN}^{\mathrm{a}} \text {, } \\
\text { PPIA }^{\mathrm{b}}, \mathrm{SHOC}^{\mathrm{b}}, \mathrm{SNCA}^{\mathrm{b}}\end{array}$ \\
\hline Nucleus & DUSP9 $^{\mathrm{a}}, \mathrm{TFAP} \mathrm{B}^{\mathrm{b}}$ \\
\hline
\end{tabular}

${ }^{a}$ Upregulated. 'bownregulated. SPP1, secreted phosphoprotein 1; CNKSR2, connector enhancer of kinase suppressor of ras 2; HOMER3, homer scaffold protein 3; HPN, hepsin; KIT, kit proto-oncogene; PKP2, plakophilin 2; RET, ret proto-oncogene; BAIAP2L1, BAR/IMD domain containing adaptor protein 2 like 1; COMT, catechol-o-methyltransferase; KALRN, kalirin rhoGEF kinase; PPIA, peptidylprolyl isomerase A; SHOC2, SHOC2 leucine rich repeat scaffold protein; SNCA, synuclein $\alpha$; DUSP9, dual specificity phosphatase 9; TFAP2B, transcription factor AP-2 $\beta$.

Protein interaction network analysis. Protein function is regulated and mediated by interaction with other proteins (23). By querying the protein interaction database and the associated literature, a protein interaction network was constructed (Fig. 7) and 37 proteins with interactive associations were selected for further analysis (Table V) (24).

The protein interaction network mapped by IPA was able to identify the molecular types (including enzymes, cytokines, transcription factors, transmembrane receptors and ion channels), and the functions of these proteins. These molecules
Table VIII. Expression of common differentially expressed genes between disease-associated networks.

\begin{tabular}{|c|c|}
\hline Network & Common genes \\
\hline 5.3 .1 & $\mathrm{KALRN}^{\mathrm{a}}, \mathrm{CNKSR}^{\mathrm{a}}, \mathrm{COMT}^{\mathrm{a}}, \mathrm{SHOC}^{\mathrm{b}}{ }^{\mathrm{p}}, \mathrm{PKP}^{\mathrm{a}}$ \\
\hline 5.3 .2 & $\mathrm{SNCA}^{\mathrm{b}}, \mathrm{KIT}^{\mathrm{a}}, \mathrm{TFAP}^{2} \mathrm{~B}^{\mathrm{b}}, \mathrm{BAIAP}^{2} \mathrm{~L}^{\mathrm{a}}{ }^{\mathrm{a}}, \mathrm{RET}^{\mathrm{a}}$ \\
\hline 5.3 .3 & DUSP9 $^{\mathrm{a}}$, PPIA $^{\mathrm{b}}$ \\
\hline 5.3 .4 & - \\
\hline 5.3 .5 & HPN, ${ }^{a} S P P 1^{a}, H_{O M E R} 3^{a}$ \\
\hline
\end{tabular}

${ }^{a}$ Upregulated. 'Downregulated. KALRN, kalirin rhoGEF kinase; CNKSR2, connector enhancer of kinase suppressor of ras 2; COMT, catechol-o-methyltransferase; SHOC2, SHOC2 leucine rich repeat scaffold protein; PKP2, plakophilin 2; SNCA, synuclein $\alpha$; KIT, kit proto-oncogene; KIT, kit proto-oncogene; TFAP2B, transcription factor AP-2 $\beta$; BAIAP2L1, BAR/IMD domain containing adaptor protein 2 like 1; RET, ret proto-oncogene; DUSP9, dual specificity phosphatase 9; PPIA, peptidylprolyl isomerase A; HPN, hepsin; SPP1, secreted phosphoprotein 1; HOMER3, homer scaffold protein 3.

comprised 11 enzymes, one cytokine, two growth factors, two transcription factors, seven ion channels, one transmembrane receptor, one nuclear receptor and 12 others (Table VI).

The interaction network was screened and certain genes with high connectivity were selected for subsequent analysis. A total of 16 genes were screened expressing catecholO-methyltransferase (COMT), KIT proto-oncogene, receptor tyrosine kinase (KIT), secreted phosphoprotein (SPP)1, hepsin (HPN), RET, neurotrophin (NTF)3, dual specificity phosphatase (DUSP)9, plakophilin (PKP)2, 

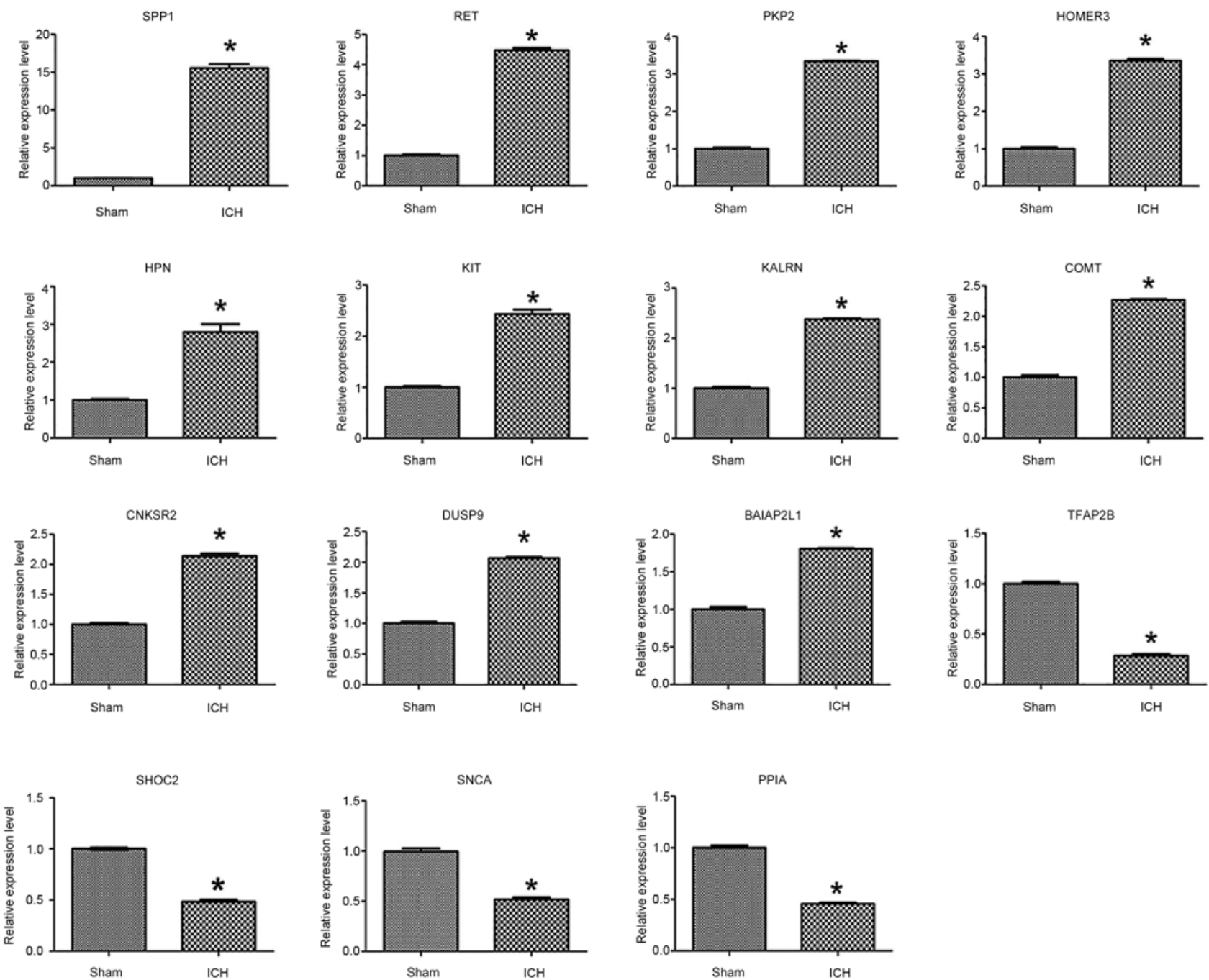

Figure 8. Reverse transcription-quantitative PCR was used to detect the expression changes of associated genes in perihematoma tissue in the sham and ICH groups. mRNA expression levels were normalized to those of $\beta$-actin. " $\mathrm{P}<0.05$ vs. sham. ICH, intracerebral hemorrhage; SPP1, secreted phosphoprotein 1; HPN, hepsin; RET, ret proto-oncogene; DUSP9, dual specificity phosphatase 9; PKP2, plakophilin 2; HOMER3, homer scaffold protein 3; KALRN, kalirin rhoGEF kinase; CNKSR2, connector enhancer of kinase suppressor of ras 2; BAIAP2L1, BAR/IMD domain containing adaptor protein 2 like 1; TFAP2B, transcription factor AP-2 $\beta$; SNCA, synuclein $\alpha$; PPIA, peptidylprolyl isomerase A; SHOC2, SHOC2 leucine rich repeat scaffold protein; COMT, catechol-o-methyltransferase.

homer scaffold protein (HOMER)3, kalirin RhoGEF kinase (KALRN), connector enhancer of kinase suppressor of Ras (CNKSR2), BAR/IMD domain-containing adaptor protein 2-like 1 (BAIAP2L1), transcription factor AP-2 $\beta$ (TFAP2B), synuclein $\alpha$ (SNCA), peptidylprolyl isomerase A (PPIA) and SHOC2 leucine rich repeat scaffold protein (SHOC2). After comparing these with the differential expression profiles, 11 upregulated (SPP1, DUSP9, COMT, BAIAP2L1, PKP2, HOMER3, RET, KIT, HPN, CNKSR2 and KALRN) and four downregulated genes (TFAP2B, PPIA, SHOC2 and SNCA) were identified; a total of 15 differentially expressed genes were therefore selected for further investigation. Of these, one was located in the outer membrane, six were in the plasma membrane, six were in the cytoplasm, and two were in the nucleus (Table VII).

$R T-q P C R$ verification analysis. RT-qPCR verification was performed on the 15 differentially expressed genes screened; expression levels of all 15 genes significantly changed following ICH. TFAP2B, SHOC2, SNCA and PPIA were downregulated, all the other genes were upregulated (Fig. 8).

Association between differentially expressed gene profile and nervous system development following ICH. Using Venny 2.1.0 software, the 15 selected differentially expressed genes were compared and analyzed with disease-associated networks (Fig. 9). This revealed that five differentially expressed genes (14.3\%) overlapped in the 'nervous system development', 'cell development' and 'neurological disease' networks (5.3.1). There were five common genes within the 'cell development', 'embryonic development' and 'development of the nervous system' networks (5.3.2), accounting for $16.1 \%$. Additionally, there were two common genes with respect to 'cell structure and function' and 'developmental disease' networks (5.3.3), accounting for 6.1\%; however, there were 0 common genes $(0 \%)$ within 'cardiovascular disease' and 'nervous system disease' (5.3.4). A total of three common genes were identified in 'organismal injury 

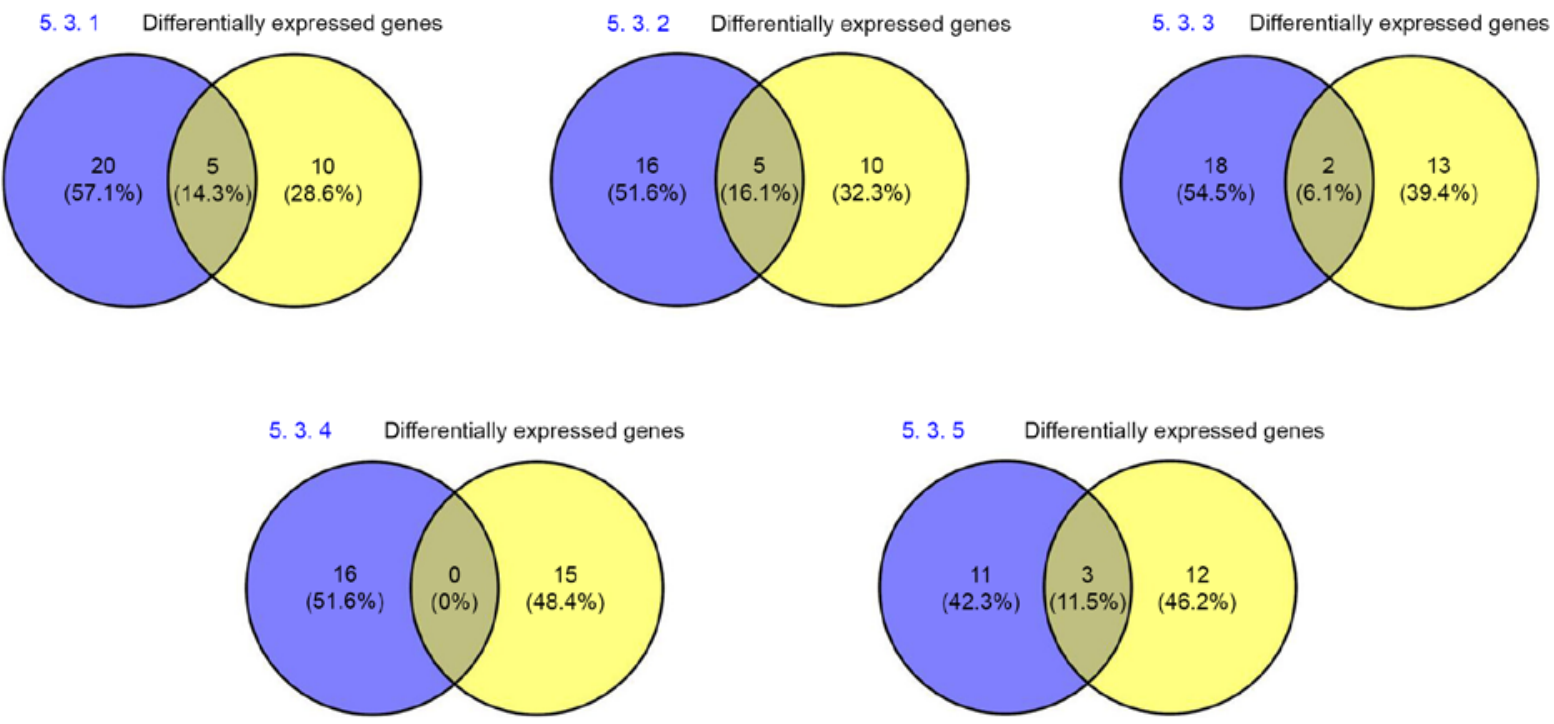

Figure 9. Comparative analysis of differentially expressed genes and disease-associated networks. Venny 2.1 .0 software was used to compare and analyze 15 differentially expressed genes and disease-associated networks that were screened out.

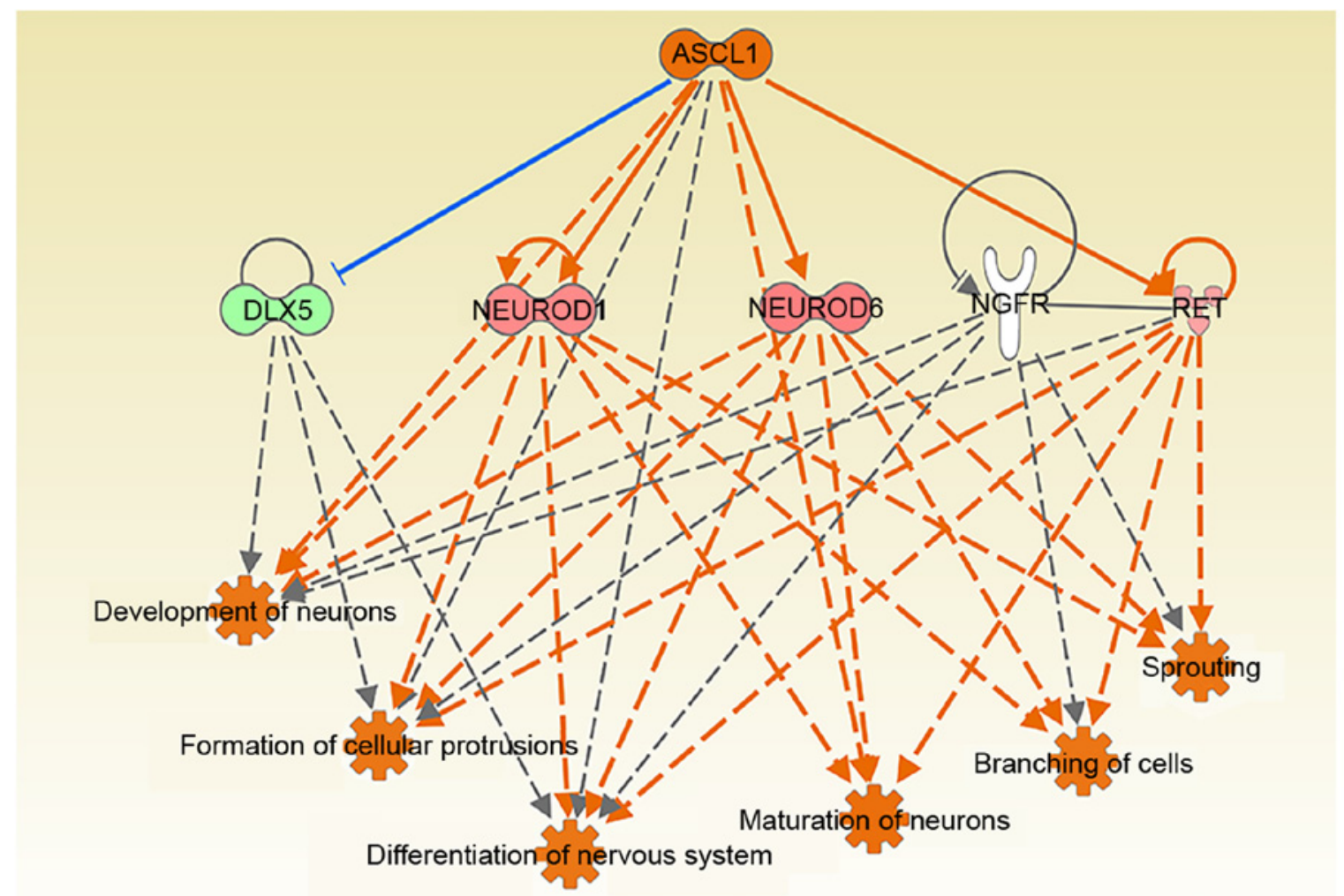

Figure 10. Ingenuity Pathway Analysis software was used to analyze the activation of upstream regulatory effect pathways associated with 'nervous system development and function'.

and abnormalities', accounting for $11.5 \%$ of the total $(5.3 .5$; Fig. S2; Table VIII).

Analysis of the association with 'neurological diseases' indicated that the changes in the perihematoma microenvironment following ICH were associated with 'development (repair) of the nervous system'. Subsequently, IPA software was used to analyze the causal network of neural functional development. This analysis showed that only effects of
Achaete-scute homolog 1 (ASCL1) were activated, and this gene was associated with 'cell growth' and 'neuron development (repair)' (Fig. 10). ASCL1 mediated cell functions such as 'germination', 'extension', 'neuron maturation', 'development' and 'synaptic formation' by regulating RET (Fig. 11A and B). Furthermore, it was possible to detect the upregulation of RET and its colocalization with neurons in rats following $\mathrm{ICH}$ (Fig. 11C-N). Therefore, further investigation of the repair 
A

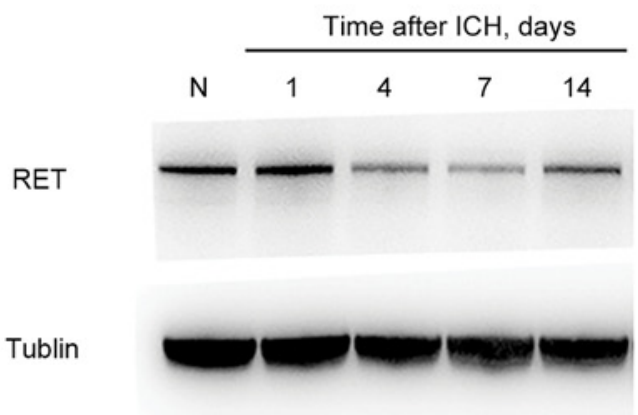

B

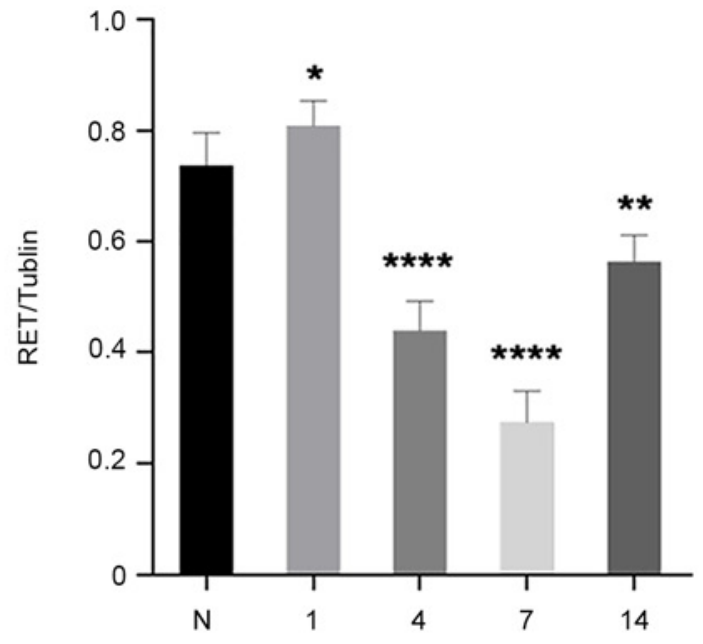

C

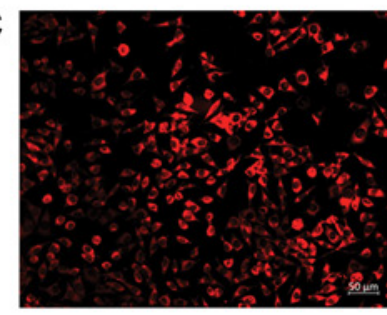

G

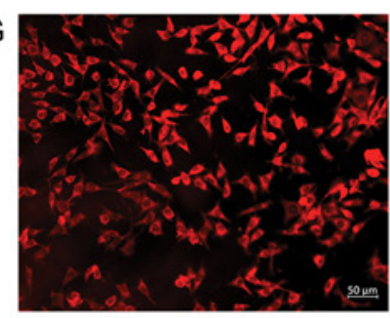

$\mathrm{K}$

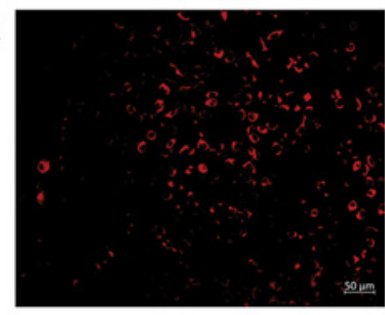

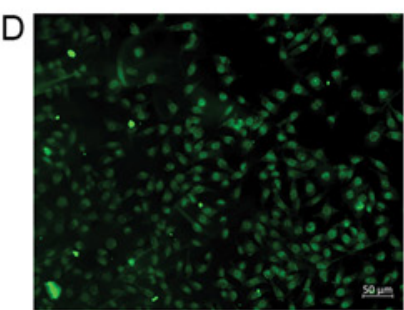
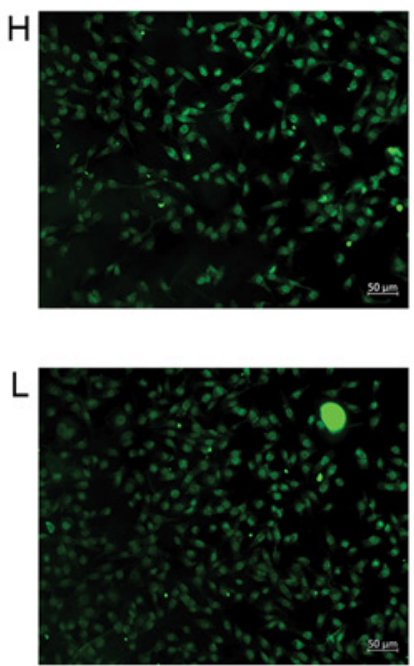
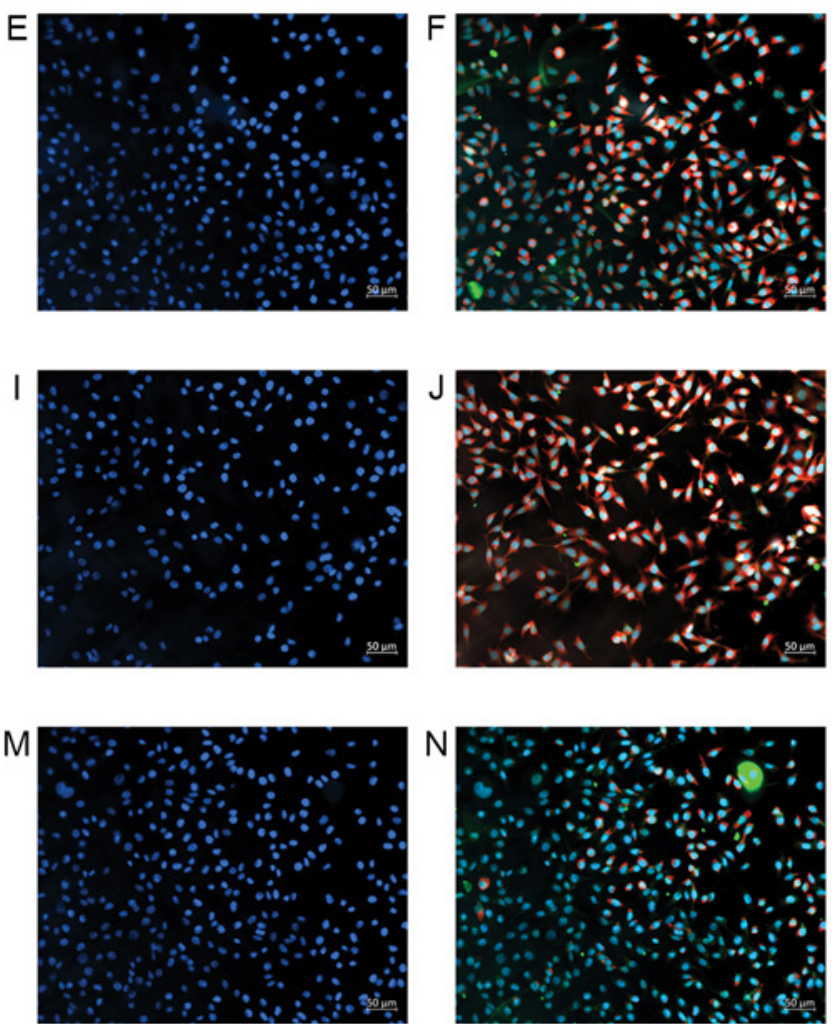

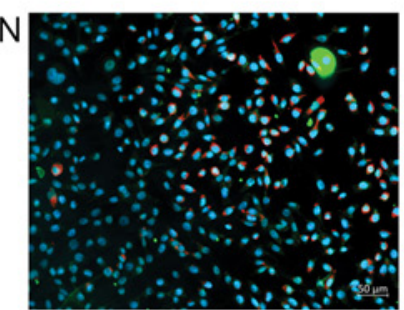

Figure 11. Expression of RET in rats following ICH. (A) Expression changes and (B) analysis of RET at different time points following ICH in rats (n=6). ${ }^{*} \mathrm{P}<0.05,{ }^{* *} \mathrm{P}<0.01,{ }^{* * * *} \mathrm{P}<0.0001$ vs. N. Immunofluorescence of (C) NeuN, (D) RET and (E) Hoechst staining in the perihematoma region of the sham group. (F) Merged immunofluorescence in the sham group (n=6). Immunofluorescence of (G) NeuN, (H) RET and (I) Hoechst staining at 1 day post-ICH. (J) Merged immunofluorescence at 1 day post-ICH. Immunofluorescence of (K) NeuN, (L) RET and (M) Hoechst at 7 days post-ICH. (N) Merged immunofluorescence at 7 days post-ICH. ICH, intracerebral hemorrhage; $\mathrm{N}$, normal control; RET, ret proto-oncogene.

function of this pathway axis of the ASCL1-RET-nervous system will be an object for future research.

\section{Discussion}

$\mathrm{ICH}$ is an acute and severe disease of the central nervous system, which endangers the health of the public and brings a heavy burden on families and society (25). Current knowledge suggests that $\mathrm{ICH}$ not only includes primary lesions caused by hematoma (for example, hematoma formation and the placeholder effect of expansion, which causes direct damage to perihematoma tissue) but also includes agents indirectly responsible for secondary damage. These include toxic substances triggered by the burst of erythrocytes, a highly active metabolic state, spreading depression, oxidative stress, toxic effects of excitatory amino acids and inflammation in perihematoma tissue, which causes secondary damage $(25,26)$. This is referred to as a microenvironment change in the perihematoma following $\mathrm{ICH}(1,4,12)$. The functions of the microenvironment are diverse, including regulation of the blood flow and metabolism, modulation of substance exchange across the blood-brain barrier, trophic support and repair of injured neurons (26). Primary post-ICH injury is often unforeseeable, and therefore potential intervention strategies, such 
as neuroprotection, are limited (26). Consequently, secondary injury in the peripheral hematoma following $\mathrm{ICH}$ is an important factor in neurological impairment and is a challenge for translational medicine.

In the present study, an ICH model was constructed by injecting autologous venous-tail blood into the basal ganglia region of the brain in rats, and the success of the construction of the ICH model was assessed using the neural dysfunction scoring method (comprising the forelimb placement and the corner turn test). Between $6 \mathrm{~h}$ and 7 days post-ICH, neural dysfunction in rats with limb paralysis was significantly increased compared with the sham group. Apoptosis is an important contributor towards nerve function defect in neurons in the perihematoma following ICH (16); the present study showed that, from $12 \mathrm{~h}$ to 4 days post-ICH, neuron apoptosis increased compared with the sham group, and apoptosis peaked on day 2 post-surgery. In addition, immunofluorescence co-localization experiments showed that the neuronal proteins tagged were the neuronal nuclear antigen NeuN and the apoptotic protein cleaved caspase-3, thereby suggesting that apoptosis in perihematoma following ICH primarily occurred in neurons.

The perihematoma tissue in rats 1 day after the operation was screened using Agilent microarray detection assay. As shown by the Pearson correlation coefficient, boxplot and cluster map, significant differences in gene expression were identified in the perihematoma of the sham and $\mathrm{ICH}$ groups at 1 day post-ICH, among which 210 genes were up- and 173 were downregulated; differences in expression levels of 24,150 were not statistically significant. GO functional annotation showed that the differentially expressed genes were most relevant to 'biological regulation', 'ion balance', 'regulation of cellular processes', 'pain sensation', 'external stimuli' and 'regulation of stress'. Molecular functions were primarily associated with 'hormone activity', 'oxygen transporter activity' and activation of a series of ion channels. Cell component was associated with 'extracellular region' and 'plasma membrane'. Therefore, based on GO functional annotation, it was possible to conclude that the changes in gene expression profiles in the peripheral hematoma region following $\mathrm{ICH}$ were primarily associated with external stimulation, which exerted harmful/beneficial effects, such as neuron protection/neuronal apoptosis, via activating ion channels (receptors) on the cell membrane and regulating the intracellular biological (stress) responses (25-27). Using IPA, enrichment of the classical signaling pathways of the differentially expressed genes in the post-ICH perihematoma was further studied. This analysis identified nine of the most significant enrichment pathways for these differentially expressed genes, including: 'Thyroid cancer signaling' [3/38; NTF3, brain-derived neurotrophic factor (BDNF), RET]; 'c-Huntington's Disease signaling' [6/232; neuronal differentiation 1, BDNF, proenkephalin, G protein subunit $\alpha 14$, SNCA, heat shock protein family A (Hsp70) member 2]; 'L-DOPA degradation' (1/2; COMT); 'taurine biosynthesis' [1/2; cysteine dioxygenase type 1 (CDO1)]; 'arginine degradation I (arginase pathway)' [1/4; arginase 1 (ARG1)]; 'L-cysteine degradation I' (1/4; CDO1); 'role of osteoblasts, osteoclasts and chondrocytes in rheumatoid arthritis' (5/224; collagen type I $\alpha 1$ chain, SPP1, distal-less homeobox 5, calcitonin receptor, Wnt family member 4); 'urea cycle' (1/6; ARG1); and 'arginine degradation VI (arginase 2 pathway)' (1/6; ARG1; Table III). However, the z-scores did not reveal any significant activation or inhibition of the signaling pathways. PANTHER analysis suggested that changes in gene expression profiles following ICH were primarily enriched in 'oxidative stress response'. Using IPA software, associations between differentially expressed genes and diseases were then analyzed. This indicated that changes in these differentially expressed genes were primarily associated with 'nervous system development' and 'neurological diseases'. After analyzing these disease-associated networks and differentially expressed genes in rats, a series of differentially expressed genes associated with disease function were identified. Based on functional annotation of these associated genes, it was possible to determine that changes in the expression chip profile of the hematoma in rats following $\mathrm{ICH}$ were primarily linked with 'nervous system development'. Considered with the biological phenomena associated with pathological status following $\mathrm{ICH}$, such as neuron apoptosis, these differentially expressed genes were suggested to be most closely associated with 'repair of nerve function' in the perihematoma following ICH.

Protein function is regulated and mediated by interaction with other proteins. Protein interaction network analysis of differentially expressed genes following $\mathrm{ICH}$ in rats was performed to classify 37 proteins according to molecular type; this included 10 enzymes, one cytokine, two growth factors, two transcription factors, seven ion channels, one transmembrane receptor, one nuclear receptor and 12 others. Associated proteins from the protein interaction network for selected for further study, which led to the identification of 11 genes (SPP1, DUSP9, COMT, BAIAP2L1, PKP2, HOMER3, RET, KIT, HPN, CNKSR2 and KALRN) that were upregulated and four (TFAP2B, PPIA, SHOC2 and SNCA) that were downregulated. Furthermore, these genes were confirmed via RT-qPCR and cell localization analysis; the results showed that one protein was localized in the extracellular domain, six were in the plasma, six were in the cytoplasm and two were in the nuclei. This was consistent with the results of GO functional annotation, indicating that these 15 differentially expressed genes were the most essential in terms of tissue damage in the peripheral hematoma following $\mathrm{ICH}$.

Venny 2.1.0 software was used to compare and analyze the 15 selected differentially expressed genes and disease-associated networks. A total of five common genes (14.3\%) were identified between the differentially expressed genes and 'nervous system development', 'cell development' and 'neurological diseases'. A total of five common genes were associated with 'cell development', 'embryonic development' and 'nervous system development', accounting for $16.1 \%$; there were two common genes with respect to 'cell structure and function' and 'developmental diseases', accounting for 6.1\%. Additionally, there were three common genes associated with 'organismal injury and abnormalities', which accounted for $11.5 \%$, and 0 genes $(0 \%)$ in common between 'cardiovascular disease' and 'nervous system disease'. These findings were consistent with the previous finding that changes in gene expression identified via microarray expression assay in the peripheral hematoma region following $\mathrm{ICH}$ are those of genes most closely associated with repair of the nervous system (27). Subsequently, IPA was used to analyze the causal network of neural functional development. This analysis showed that only ASCL1 was activated; this protein is associated with 'cell growth' and 'neuron development (repair)'. Among the candidate genes, ASCL1 
mediated 'cell germination', 'extension', 'neuron maturation', 'development and synaptic formation' via regulating RET. Additionally, western blotting and immunofluorescence experiments revealed upregulation of RET in perihematoma tissue in rats following $\mathrm{ICH}$ and localization of RET in the neurons. The present results suggested that the ASCL1-RET-nerve repair signal axis may serve a key role in repair of nerve damage in the peripheral hematoma region following $\mathrm{ICH}$; this may provide an avenue for further investigation of the nerve repair function in the perihematoma microenvironment following $\mathrm{ICH}$.

\section{Acknowledgements}

Not applicable.

\section{Funding}

The present study was supported by the National Natural Science Foundation of China (grant nos. 81901195 and 81873742) and Postgraduate Research \& Practice Innovation Program of Jiangsu Province (grant no. SJCX19_0864).

\section{Availability of data and materials}

The datasets generated and/or analyzed during the current study are available in the Gene Expression Omnibus repository, accession no. GSE171144.

\section{Authors' contributions}

JW participated in study design, performed the experiments and wrote the manuscript. YC conceived the study and performed the experiments. JL designed the experiments. MC performed western blot and statistical analysis. JS analyzed the data and approved the manuscript and revised it critically for important intellectual content. KK made substantial contributions to acquisition of data, revised and approved the manuscript. JS, KK and JW confirm the authenticity of all the raw data. All authors read and approved the final manuscript.

\section{Ethics approval and consent to participate}

The present study was approved by the Animal Care and Use Committee in Nantong University (approval no. S20180816-012).

\section{Patient consent for publication}

Not applicable.

\section{Competing interests}

The authors declare they have no competing interests.

\section{References}

1. Carcel C, Sato S, Zheng D, Heeley E, Arima H, Yang J, Wu GJ, Chen GF, Zhang SH, Delcourt C, et al: Prognostic significance of hyponatremia in acute intracerebral hemorrhage: Pooled analysis of the intensive blood pressure reduction in acute cerebral hemorrhage trial studies. Crit Care Med 44: 1388-1394, 2016.
2. Li WJ, Jin C, Vaidya A, Wu YT, Rexrode K, Zheng XM, Gurol ME, Ma C, Wu SL and Gao X: Blood pressure trajectories and the risk of intracerebral hemorrhage and cerebral infarction: A prospective study. Hypertension 70: 508-514, 2017.

3. Qiu M, Sato S, Zheng D, Wang X, Carcel C, Hirakawa Y, Sandset EC, Delcourt C, Arima H, Wang J, et al: Admission heart rate predicts poor outcomes in acute intracerebral hemorrhage: The intensive blood pressure reduction in acute cerebral hemorrhage trial studies. Stroke 47: 1479-1485, 2016.

4. Yang J, Arima H, Wu G, Heeley E, Delcourt C, Zhou J, Chen G, Wang X, Zhang S, Yu S, et al: Prognostic significance of perihematomal edema in acute intracerebral hemorrhage: Pooled analysis from the intensive blood pressure reduction in acute cerebral hemorrhage trial studies. Stroke 46: 1009-1013, 2015.

5. Wang X, Arima H, Heeley E, Delcourt C, Huang Y, Wang JG, Stapf C, Robinson T, Woodward M, Chalmers J, et al: Magnitude of blood pressure reduction and clinical outcomes in acute intracerebral hemorrhage: Intensive blood pressure reduction in acute cerebral hemorrhage trial study. Hypertension 65: 1026-1032, 2015.

6. Wu J, Sun L, Li H, Shen H, Zhai W, Yu Z and Chen G: Roles of programmed death protein 1/programmed death-ligand 1 in secondary brain injury after intracerebral hemorrhage in rats: Selective modulation of microglia polarization to anti-inflammatory phenotype. J Neuroinflammation 14: 36, 2017.

7. Zeng Z, Liu H and Jiang D: NRH2 induces cell apoptosis of cerebral tissues around hematomas after intracerebral hemorrhage through up-regulating proNGF, sortilin and p75NTR expressions. Xi Bao Yu Fen Zi Mian Yi Xue Za Zhi 31: 532-536, 539, 2015 (In Chinese)

8. Zhao X, Ting SM, Liu CH, Sun G, Kruzel M, Roy-O'Reilly M and Aronowski J: Neutrophil polarization by IL-27 as a therapeutic target for intracerebral hemorrhage. Nat Commun 8: 602, 2017.

9. Xi T, Jin F, Zhu Y, Wang J, Tang L, Wang Y, Liebeskind DS and He Z: MicroRNA-126-3p attenuates blood-brain barrier disruption, cerebral edema and neuronal injury following intracerebral hemorrhage by regulating PIK3R2 and Akt. Biochem Biophys Res Commun 494: 144-151, 2017.

10. Guerrero WR, Gonzales NR, Sekar P, Kawano-Castillo J, Moomaw CJ, Worrall BB, Langefeld CD, Martini SR, Flaherty ML, Sheth KN, et al: Variability in the use of platelet transfusion in patients with intracerebral hemorrhage: Observations from the ethnic/racial variations of intracerebral hemorrhage study. J Stroke Cerebrovasc Dis 26: 1974-1980, 2017.

11. Chen-Roetling J, Kamalapathy P, Cao Y, Song W, Schipper HM, and Regan RF: Astrocyte heme oxygenase-1 reduces mortality and improves outcome after collagenase-induced intracerebral hemorrhage. Neurobiol Dis 102: 140-146, 2017.

12. Urday S, Beslow LA, Dai F, Zhang F, Battey TW, Vashkevich A, Ayres AM, Leasure AC, Selim MH, Simard JM, et al: Rate of perihematomal edema expansion predicts outcome after intracerebral hemorrhage. Crit Care Med 44: 790-797,2016.

13. Chiang CC, Meyer DM, Meyer BC, Agrawal K and Modir R: RAcial Disparities in Ich after IV-tPA and Neurointerventional Treatment (RADIANT). J Stroke Cerebrovasc Dis 29: 104474, 2019.

14. Viader A, Chang LW, Fahrner T, Nagarajan R and Milbrandt J: MicroRNAs modulate Schwann cell response to nerve injury by reinforcing transcriptional silencing of dedifferentiation-related genes. J Neurosci 31: 17358-17369, 2011.

15. Nagarajan R, Le N, Mahoney $\mathrm{H}$, Araki $\mathrm{T}$ and Milbrandt $\mathrm{J}$ : Deciphering peripheral nerve myelination by using schwann cell expression profiling. Proc Natl Acad Sci USA 99: 8998-9003, 2002.

16. de Jonge RR, Vreijling JP, Meintjes A, Kwa MS, van Kampen AH, van Schaik IN and Baas F: Transcriptional profile of the human peripheral nervous system by serial analysis of gene expression. Genomics 82: 97-108, 2003.

17. Wu H, Wang J, Cao M, Liang J, Wu D, Gu X and Ke K: Effects of homocysteine-induced endoplasmic reticulum protein on endoplasmic reticulum stress, autophagy, and neuronal apoptosis following intracerebral hemorrhage. IBRO Rep 9: 207-217, 2020.

18. Shen J, Liu Y, Song Y, Li L, Duan C, Zhou Y and Ke K: CHMP4B, ESCRT-III associating protein, associated with neuronal apoptosis following intracerebral hemorrhage. Brain Res 1597: 1-13, 2015.

19. Hua Y, Nakamura T, Keep RF, Wu J, Schallert T, Hoff JT and Xi G: Long-term effects of experimental intracerebral hemorrhage: The role of iron. J Neurosurg 104: 305-312, 2006. 
20. Cao M, Ke K, Sun H and Robertson A: Effects of prostaglandin E1 on perihematomal tissue after hypertensive intracerebral hemorrhage. Acta Neurol Taiwan 20: 172-181, 2011.

21. Livak KJ and Schmittgen TD: Analysis of relative gene expression data using real-time quantitative PCR and the 2(-Delta Delta C(T)) method. Methods 25: 402-408, 2001.

22. Ding W, Chen R, Wu C, Chen W, Zhang H, Fan X, Wang H, Ji Y, Xie L, Ning $X$ and Shen L: Increased expression of HERPUD1 involves in neuronal apoptosis after intracerebral hemorrhage. Brain Res Bull 128: 40-47, 2017.

23. Zhou T, Wang H, Shen J, Li W, Cao M, Hong Y and Cao M The p35/CDK5 signaling is regulated by p75NTR in neuronal apoptosis after intracerebral hemorrhage. J Cell Physiol: Feb 15 , 2019 (Epub ahead of print).

24. Dong Z, Liu Z, Liang M, Pan J, Lin M, Lin H, Luo Y, Zhou X and Yao W: Identification of circRNA-miRNA-mRNA networks contributes to explore underlying pathogenesis and therapy strategy of gastric cancer. J Transl Med 19: 226, 2021.
25. Han X, Ren H, Nandi A, Fan X and Koehler RC: Analysis of glucose metabolism by F-FDG-PET imaging and glucose transporter expression in a mouse model of intracerebral hemorrhage. Sci Rep 11: 10885, 2021.

26. Gao L, Xu W, Li T, Chen J, Shao A, Yan F and Chen G: Stem cell therapy: A promising therapeutic method for intracerebral hemorrhage. Cell Transplant 27: 1809-1824, 2018.

27. Wang S, Xue F, Li W, Shan Y, Gu X, Shen J and Ke K: Increased expression of Triad1 is associated with neuronal apoptosis after intracerebral hemorrhage in adult rats. Int J Neurosci 130: $759-769,2020$

(i) $($ ) This work is licensed under a Creative Commons Attribution-NonCommercial-NoDerivatives 4.0 International (CC BY-NC-ND 4.0) License. 